\title{
High Loaded Mounts for Vibration Control Using Magnetorheological Fluids: Review of Design Configuration
}

\author{
Xuan Phu Do and Seung-Bok Choi \\ Smart Structures and Systems Laboratory, Department of Mechanical Engineering, Inha University, Incheon 402-751, Republic of Korea \\ Correspondence should be addressed to Seung-Bok Choi; seungbok@inha.ac.kr
}

Received 9 May 2015; Accepted 11 August 2015

Academic Editor: Chao Tao

Copyright ( 2015 X. P. Do and S.-B. Choi. This is an open access article distributed under the Creative Commons Attribution License, which permits unrestricted use, distribution, and reproduction in any medium, provided the original work is properly cited.

\begin{abstract}
Design configurations of high loaded magnetorheological (MR in short) mounts are reviewed and discussed. The configurations are analyzed on the basis of three operating modes of MR fluid: flow mode, shear mode, and squeeze mode. These modes are significantly important to develop new type of mounts and improve the efficiency of vibration control. In this paper, advantages and disadvantages of each operation mode are analyzed on the basis of ability of designing high loaded mounts. In order for analysis, the field-dependent damping force equations for typical cross sections of mounts are firstly investigated while maintaining original equations of these cross sections. As a subsequent step, simulation tools for the high loaded mounts are investigated and discussed. These tools which are developed from the analyzed method are expressed as functions of various design parameters such as inside pressure, magnetic field, dimension, stiffness, and damping. These tools are essential for accurate design of MR mount and for careful checking of the operation capability before manufacturing the mounts. This paper can provide very useful information and guidelines to determine an appropriate design configuration of high loaded mounts whose vibration control performances depend on the operational mode of MR fluid.
\end{abstract}

\section{Introduction}

The applications of MR fluids in commercial products such as automotive suspension, washing machine mounts, and motorcycle clutches are currently being more popular. In these applications, the appearance of high loaded MR mount has been recently concentrated and expanded its applications to vibration control super-weighted machines such as engine system. This application can replace the traditional rubber mount and hence improve the vibration control performance. It is remarked that the MR mount is very similar to conventional hydraulic mount and its control function of damping force and pressures can be easily achieved. Therefore, the reviews of the hydraulic mount are essential to know the operation of MR mount. The model of hydraulic mount was analyzed by Geisberger et al. [1]. The cross section of the hydraulic mount is presented as shown in Figure 1. The nonlinear model of the hydraulic mount is suggested for low and high frequency behavior of the mount. The lumped parameter linear model is used in establishing the dynamic functions of the mount as shown in Figure 2. The force transmitted to the mount base represents the sum of forces applied through the mechanical stiffness and damping parameters along with the influence of internal pressure [1]. Another survey of the hydraulic mount has been presented by Marzbani et al. [2]. There are two models of the mount for the analysis of dynamic behaviors as shown in Figure 3. The mathematical functions of these model are written as follows [2]:

$$
\begin{aligned}
\ddot{x}+2 \xi \omega_{s} \dot{x}+\omega_{s}^{2} x & =\frac{m_{e}}{m} e \omega^{2} \sin \omega t=\varepsilon e \omega^{2} \sin \omega t \\
A & =\left|\frac{X}{\varepsilon e}\right|=\frac{r^{2}}{\sqrt{\left(1-r^{2}\right)^{2}+(2 \xi r)^{2}}} \\
\ddot{z}+2 \xi \omega_{s} \dot{z}+\omega_{s}^{2} z & =Y \omega^{2} \sin \omega t \quad z=x-y
\end{aligned}
$$




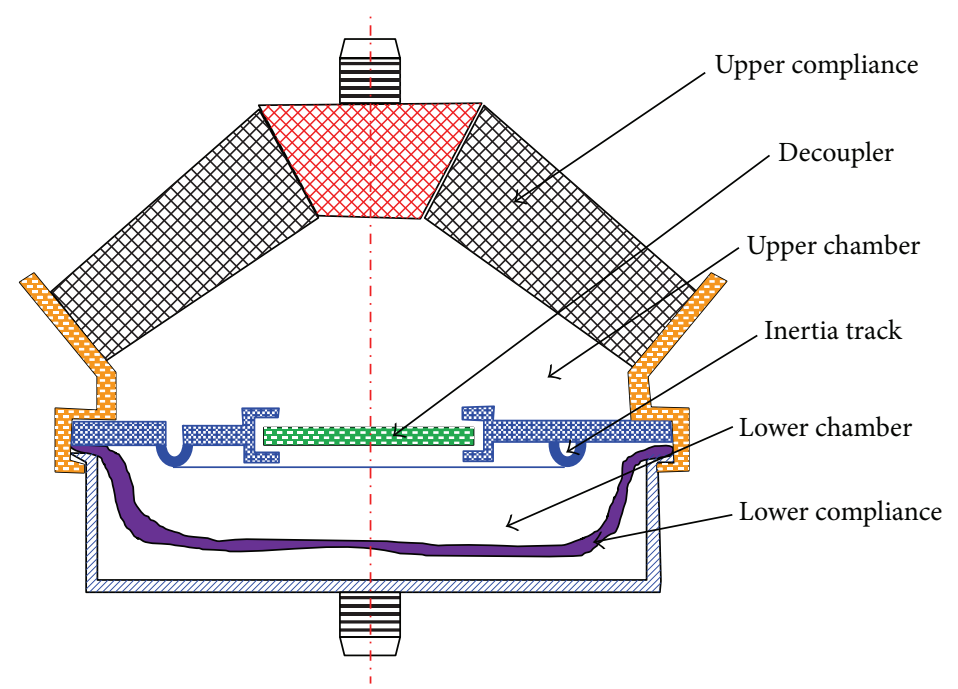

FIGURE 1: Cross section of conventional hydraulic mount.

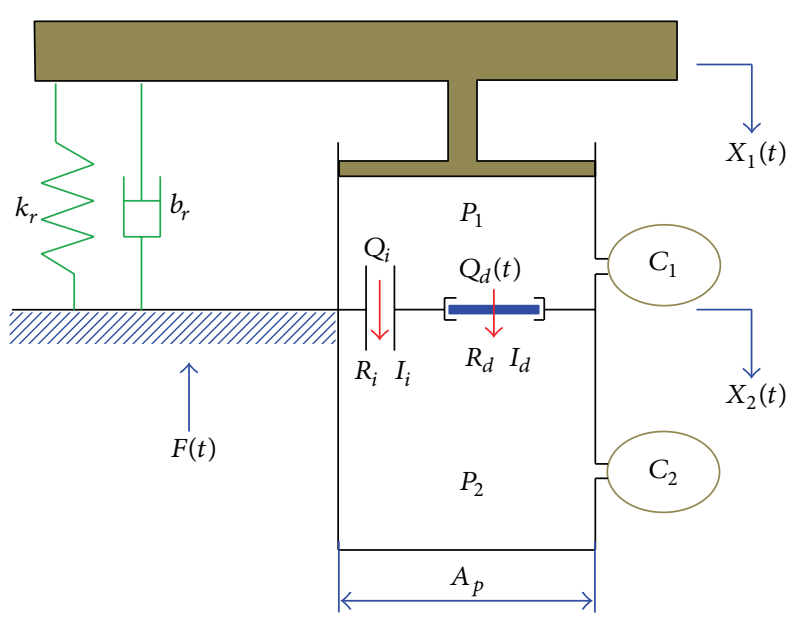

FIGURE 2: Lumped model of conventional hydraulic mount.

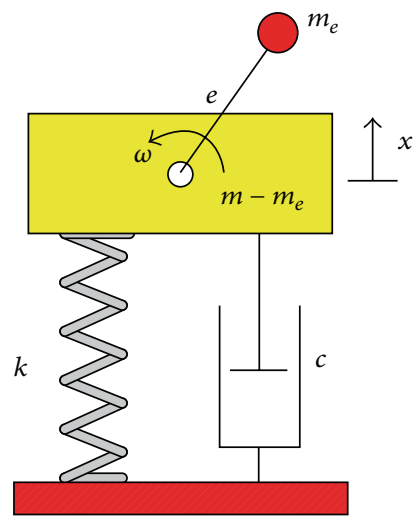

(a)

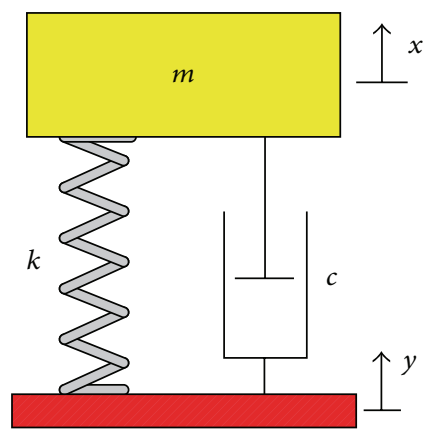

(b)

FIGURE 3: (a) Eccentric excited system and (b) base excited system. 


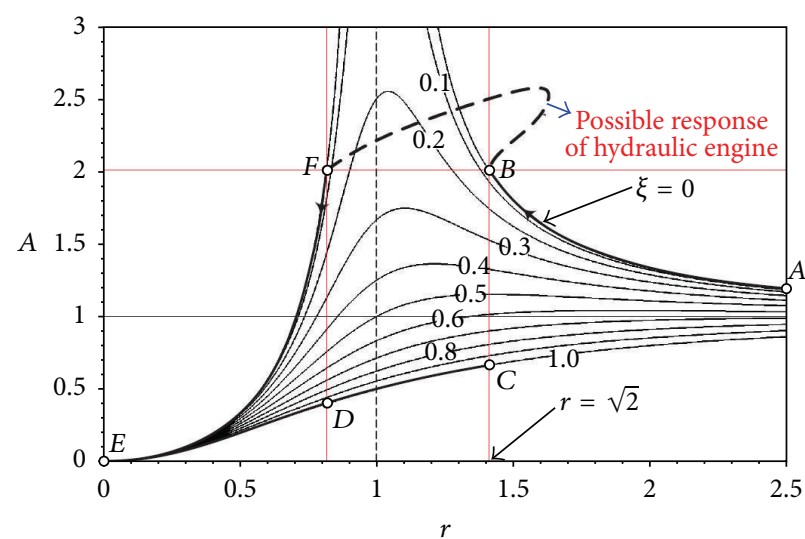

(a)

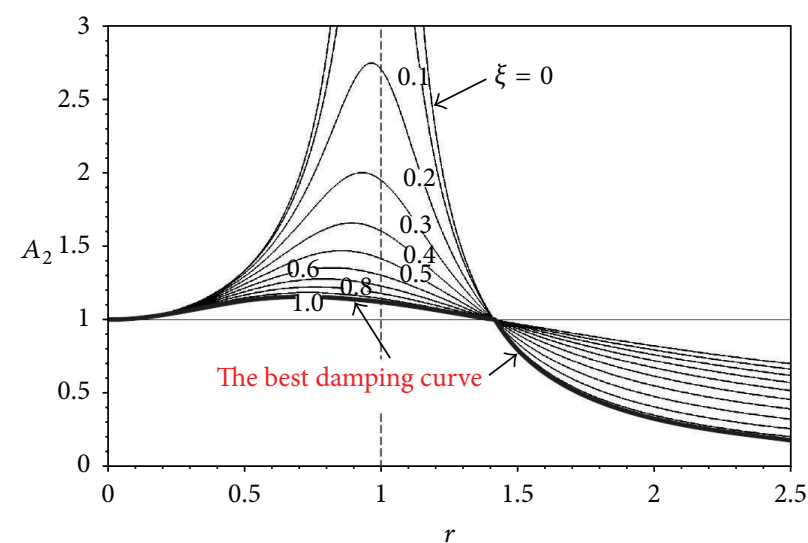

(b)

FIgURE 4: (a) Frequency response of (4) and (b) frequency response of (5).

$$
\begin{aligned}
& A_{1}=\left|\frac{Z}{Y}\right|=\frac{r^{2}}{\sqrt{\left(1-r^{2}\right)^{2}+(2 \xi r)^{2}}} \\
& A_{2}=\left|\frac{X}{Y}\right|=\frac{\sqrt{1+(2 \xi r)^{2}}}{\sqrt{\left(1-r^{2}\right)^{2}+(2 \xi r)^{2}}} .
\end{aligned}
$$

In the above, (1) and (2) are used for Figure 3(a) and (3)(5) for Figure 3(b). Following these functions, the graphs of (4) and (5) are depicted as shown in Figures 4(a) and 4(b), respectively. It is remarked from Figure 4(a) that the frequency range $r$ less than $\sqrt{2}$ has the amplitude with its value higher than the gap size of the decoupler. In this circumstance, the relative displacement $z$ is less than the gap size, and its movement will over the gap size. In Figure 4(b), the amplitude is decreased by increasing the excitation frequency, $r>1$. Hence, the strategy for mount design is to have high $\xi$ at high frequency range $r$ and small $\xi$ at low frequency range $r$. Another survey of mount using for vehicle engine has been presented by Yu et al. [3]. In this survey, elastomeric mount, passive hydraulic mount, and semiactive and active mount were reviewed. It is noted that the passive mount provides a better performance than elastomeric mount in the low frequency range. On the other hand, the active and semiactive mounts are applied to improve hydraulic mount through tuning capability. The active mount is very stiff at low frequency, which is inversely at high frequency range.

The nonlinear model of the hydraulic engine mount was studied by Golnaraghi and Jazar [4]. The flow resistance in decouple of mount is a function of decouple column fluid displacement and speed. Hence, the flow resistance increases dramatically as the decoupler plate approaches the top or bottom of its cage [4]. It is remarked that the model in this study is a basic knowledge to develop the semiactive mount afterwards. Another study of the quasilinear mount model was presented by He and Singh [5]. This model is used to estimate parameters in order to predict the transient response to realistic displacement excitations. In fact, this study analyzed the hydraulic mount models in detail which were presented in $[1,4]$. Design and optimization of the hydraulic mount were studied by Li et al. [6]. A neural network model was used to find optimized value of hydraulic mount, where its objective was used to specify the structures and materials of hydraulic mount. The application of this method removed the erroneous parameters and improved the accurate parameters. Recently, a new modified secondary path of active hydraulic mount was presented by Hausberg et al. [7]. The operation of secondary path was improved by using a moving coil and a permanent magnet since this affected the variation of rubber diaphragm. The mount using MR fluid is a kind of a semiactive type which can provide effective vibration control performance with relative simple mechanism and low cost compared to active mount. Elahinia et al. [8] presented a review of $M R$ and ER mounts. This review also presented some typical controllers for these mounts such as LQG, skyhook, ground-hook, fuzzy, neural network, and hybrid control. However, the MR mount discussed in this paper had simple structures and low capacity of damping force. Hence, in order to develop high loaded mount, these structures should be changed.

From the above analysis, a summarization of structures for designing high loaded MR mount is essential. Basically, the traditional hydraulic mount and MR mount have a very similar principles of operation. However, the capacity and controllability of these mounts are significantly different. For example, the hydraulic mount can be used passive or active, while MR mount can be used as the semiactive device which can provide controllable damping force without sensors or/and complicated control algorithms. Consequently, a broad review of design configuration of the semiactive MR mount can help designers to develop more advanced mount structures which can be applied to many industries such as automotive and civil engineering. In this paper several new structures for high loaded mount configurations utilizing MR fluids are discussed in the sense of design configuration and their benefits are also addressed in terms of vibration control performance as well as manufacturing simplicity. 


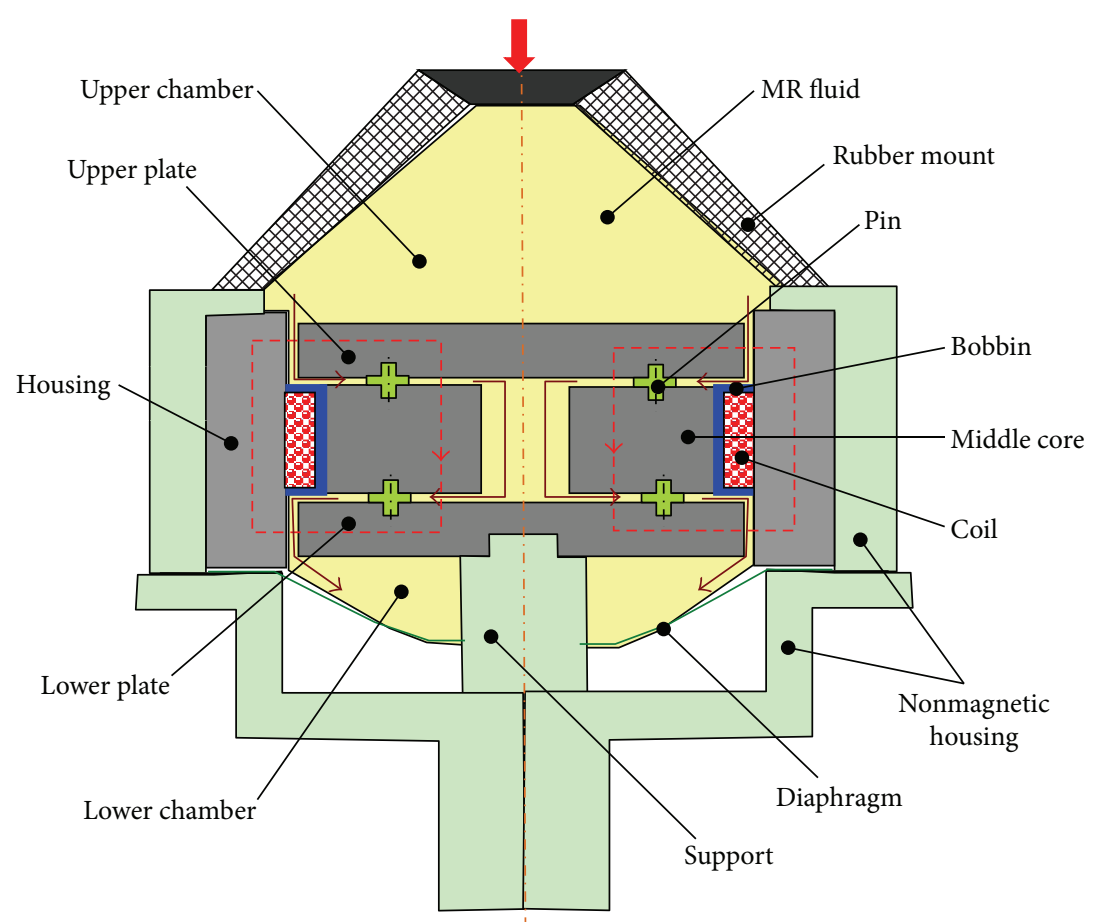

FIGURE 5: Configuration of high loaded MR mount with fixed middle core.

\section{Configurations of High Loaded MR Mounts}

In design of MR mount, three modes of MR fluid such as flow mode, shear mode, and squeeze mode are normally used. Definitions of three modes are clearly depicted in [32]. Among these operating modes, both the flow mode and shear mode are frequently used due to design simplicity as well as high control performance. In other words, the configuration structure of the flow mode and shear mode has simple section, high force, and easy manufacture. However, one disadvantage of these two modes requires a bulky design to assure desired force and to guarantee long operation. It is also noted that the damping force of the flow mode is normally higher than the case of the shear mode. On the other hand, the application of squeeze mode is difficult in design aspect because of its open gap in which the fluid leakage can easily occur. In order to make closed gap in the squeeze mode operation, an accurate sealing technique is required. Moreover, in squeeze mode configuration it is very difficult to maintain the gap to be consistent due to the variation of vertical dynamic motion. A valve structure with both annular and radial fluid flow was suggested by Wang et al. [9]. Although this structure was applied to design MR damper, it also opened a new application to design high loaded actuator. The distribution of MR paths affected the appearance of pressure which related to the damping force of actuators. A new structure of high loaded mount was firstly presented by Nguyen et al. [10]. This design used in this work has annular and flow paths to establish a high pressure inside the mount, and then the damping force can be increased. A detailed view section of this mount is depicted in Figure 5. This section is a breakthrough idea to apply the advanced smart MR fluid in mount design. Following the traditional mount, the rubber mount was used, and the MR structure was placed under the rubber mount. The combination of the rubber part and MR fluid part brings the new design concept for effective vibration control, especially in low frequency range. However, the disadvantage of this design is the choosing of small damping gap (less than $1.5 \mathrm{~mm}$ ) which may cause what is called a block-up phenomenon of MR fluid. In the blockup state MR fluid plays like a solid and hence the damping force is decreased. To prevent the block-up phenomenon of MR fluid as shown in Figure 6, a new structure of flexible valve for high loaded mount was studied by Phu et al. [11]. The middle core in [10] (Figure 5) was replaced by a moved plate in [11] (Figure 7). The motivation of this design can avoid the block-up of MR fluid to keep sufficient damping force of the mount during operation. The MR damper for integrated isolation mount was investigated by Seong et al. [12] as shown in Figure 8. In this design, a new type of seal was applied to decrease the friction which has effects on the damping force as shown in Figure 9. Detailed configuration of the mount is presented in Figure 10. This structure has the small gap $(3 \mathrm{~mm})$ between the piston head and cylinder and hence it can be used for control of tiny-vibration. However, developing this structure for high loaded mount will be limited by the large height as well as the capacity of rubber plate for seal.

A new kind of MR mount based on elastomer plate was studied by York et al. [13]. The structure of MR elastomer mount and the elastomer plate are depicted in Figures 11(a) and 11(b), respectively. The advantage of this structure is to easily prevent the leakage of MR fluid with the simple 


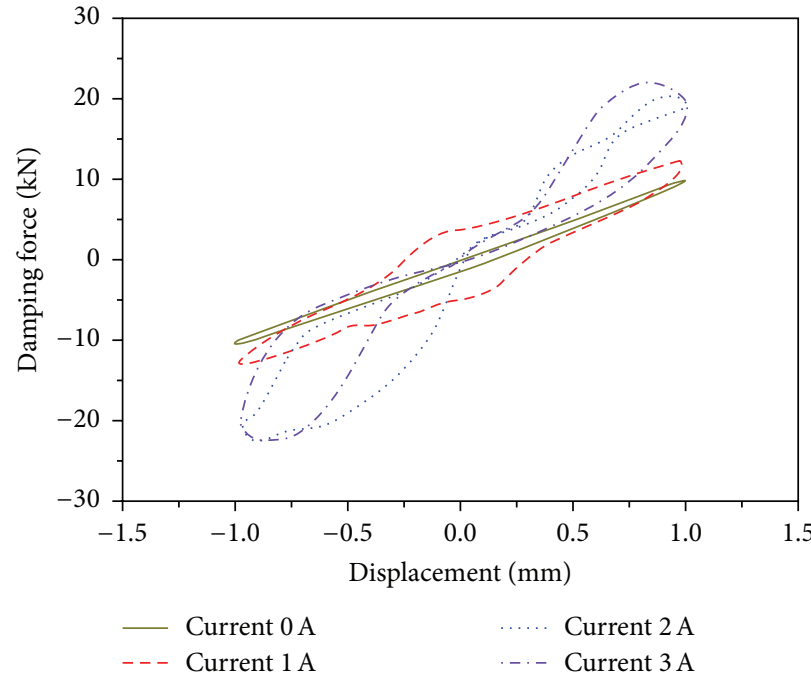

FIGURE 6: Block-up phenomenon in high loaded MR mount.

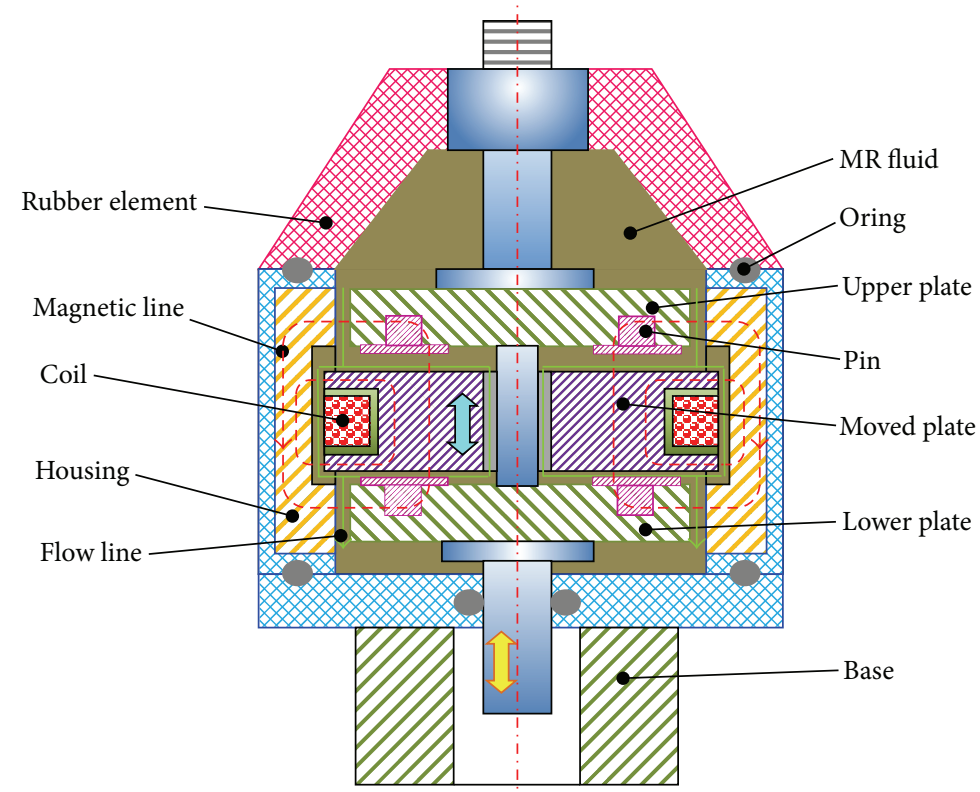

FIGURE 7: Configuration of high loaded MR mount with moved plate.

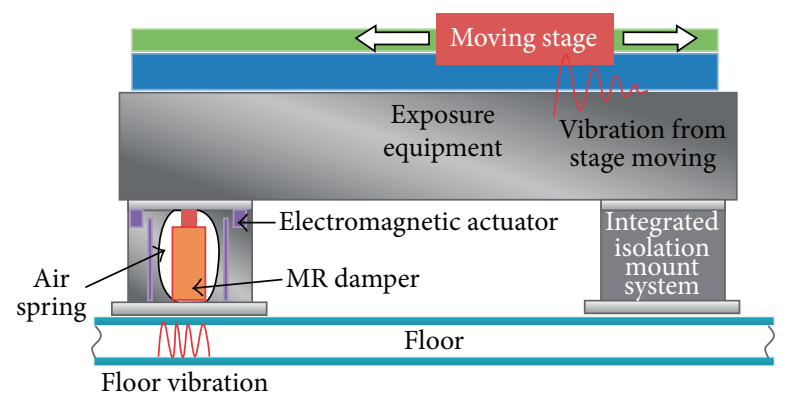

FIGURE 8: Configuration of integrated isolation mount. 


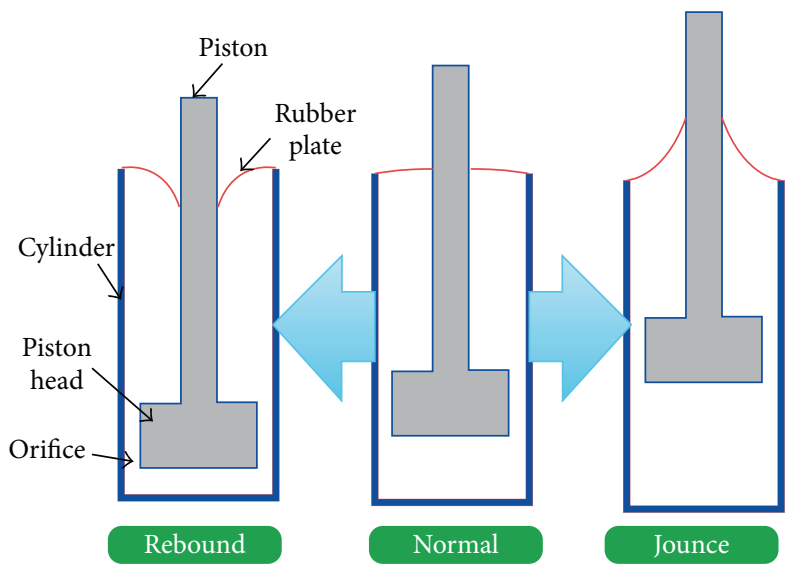

FIGURE 9: Configuration of new type of seal for integrated isolation mount.

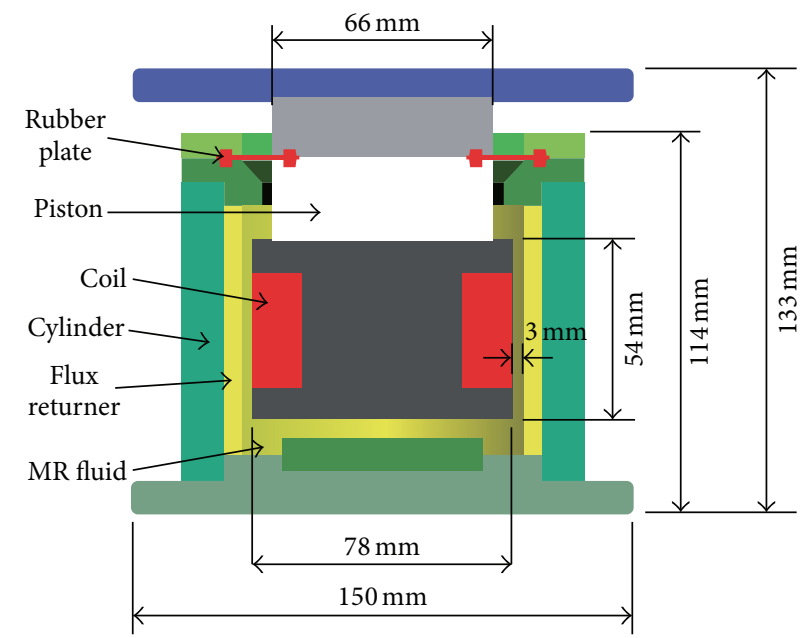

FIGURE 10: Detail configuration of integrated isolation mount.

structure. However, the damping force of this design structure is relatively low and hence it cannot apply for the high loaded MR mount which requires the high inside pressures and large damping force. A similar structure to high loaded MR mount studied in [10] was presented by Kang et al. [14] and Hung et al. [15]. The configuration of this mount is shown in Figure 12. Its advantage is to easily avoid the block-up phenomenon of MR fluid which is shown in Figure 13. On the other hand, the evaluation of a simple MR mount whose structure is very similar to the hydraulic mount shown in Figure 14 was presented by Rasekhipour and Ohadi [16]. To pursuit the high loaded mount, this mount can be used by designing the annular flow gap and retaining the section shown in Figure 14. However, the total amount of MR fluid for this design structure is very large and hence the manufacturing cost will be increased. The MR mount with the modified chamber using a coil was studied by Mansour et al. [17]. Its modification is shown in Figures 15(a) and 15(b). In this design, the modified chamber could increase the stiffness of the mount, but this increment appears around the coil. The leakage of magnetic field to the MR fluid has not been sufficient to change the state of fluid. Hence, this design structure is not good for high loaded mount and its performance is limited due to the occurrence of the block-up phenomenon of MR fluid.

The review of MR valve using for MR actuators was presented by Abd Fatah et al. [18]. This review showed cross sections of MR valve which could be applied for design mount as shown in Figure 16. This design structure can be developed for high loaded mount, but the input and output of MR fluid should be enlarged to prevent the block-up phenomenon with the space limits such as the mount height in radial direction. Recently, combination of the mount and damper was studied by Do et al. [19]. The damper-mount is a kind of the high loaded actuator which can be used for loads over $25 \mathrm{kN}$. The configuration of the damper-mount is shown in Figure 17. The movement of the piston in this design can remove the block-up phenomenon of MR fluid. In fact, this idea has been developed from $[10,14,15]$. Another design structure for high loaded MR mount was present by Chung et al. [20]. In this mount design, the damping gap is designed as inclined gap whose main function is to make smooth flow of MR fluid. The configuration of this mount is shown in Figure 18. This design with the inclined gap improves the flow 


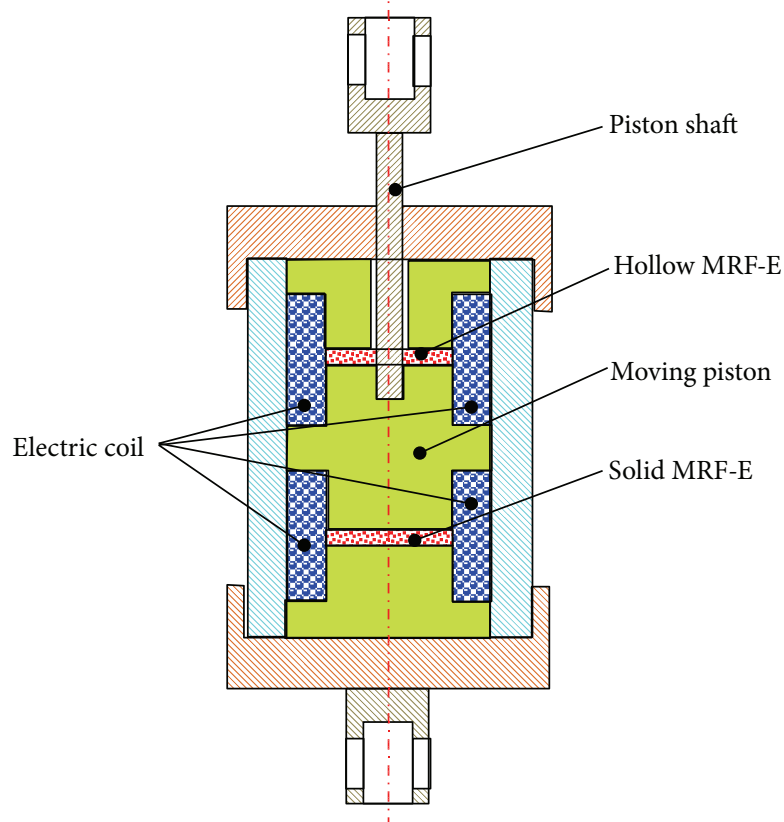

(a)

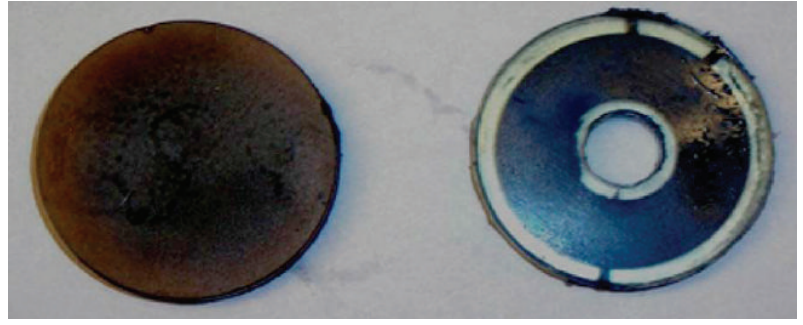

(b)

FIGURE 11: (a) Configuration of MR elastomer mount and (b) photograph of MR elastomer plate.

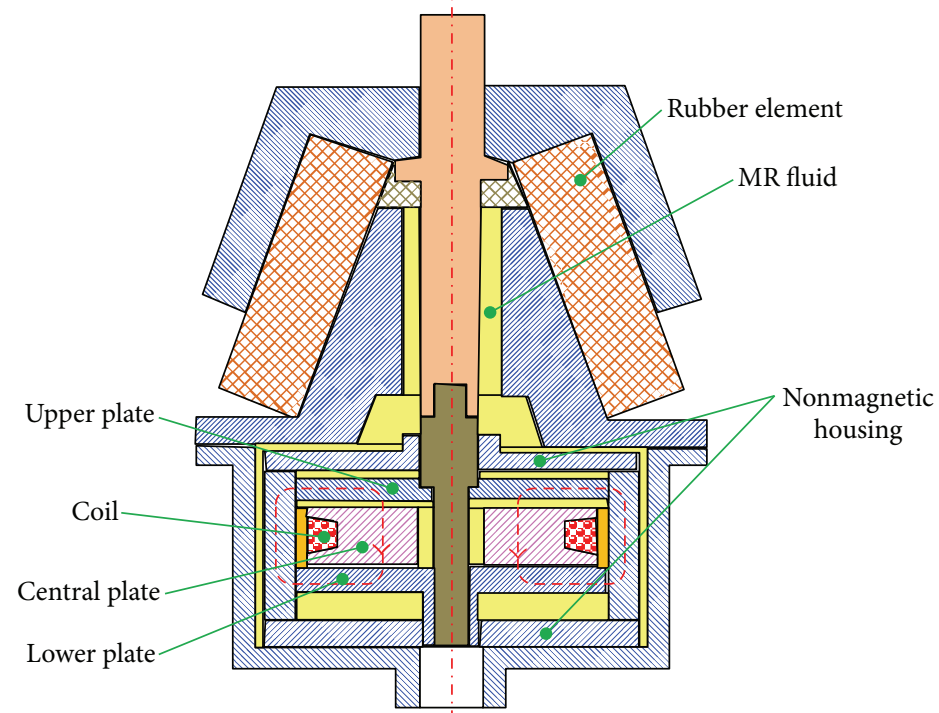

FIGURE 12: Configuration of high loaded MR mount.

motion although the distance of damping gap is longer. A traditional MR mount of the piston-type has been studied by Phu et al. [21] and its configuration is depicted in Figure 19. This structure is very simple to design mount. However, this model cannot be applied to design high loaded mount due to the requirement of large size to generate high damping force. This design structure is suitable for small damping force in the range of $300 \sim 1000 \mathrm{~N}$. The similar structure mount as piston-type was also presented by Hong et al. [22, 23] and Choi et al. [24]. The MR mount using annular flow gap was studied by Barber and Carlson [25] as shown in Figure 20.
The disadvantages of this mount are similar to the mount proposed in [15]. Another piston-type mount was also studied by Choi et al. [26], which is similar to the mount of [21, 22, 24, 25].

From the above review, design configurations of hydraulic mount, conventional MR mount, and high loaded MR mount are investigated and some salient characteristics are discussed. These intensive reviews are very helpful to develop high performance MR mount subjected to several design constraints such as space limitation and frequency limitation. It is noted that significant design factors for high loaded 


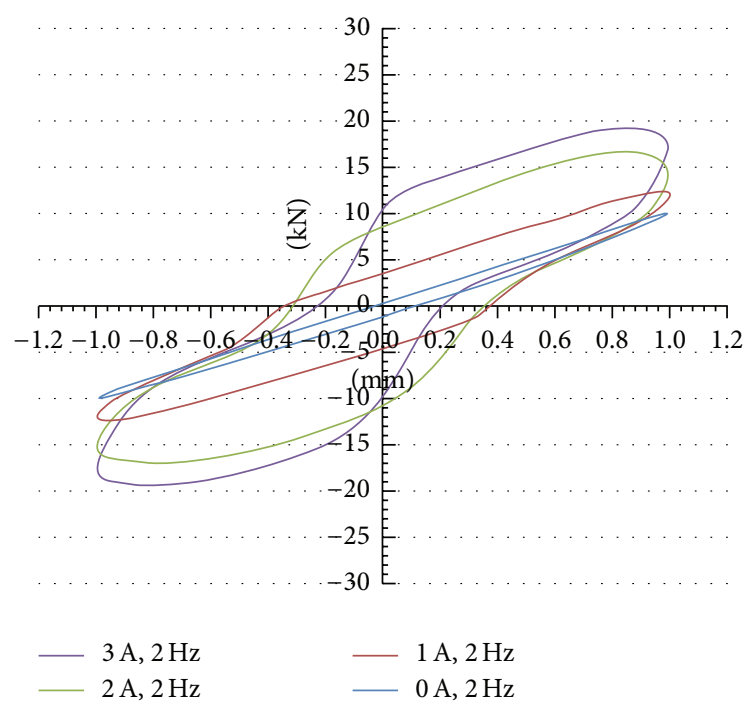

FIGURE 13: Block-up phenomenon of MR mount.

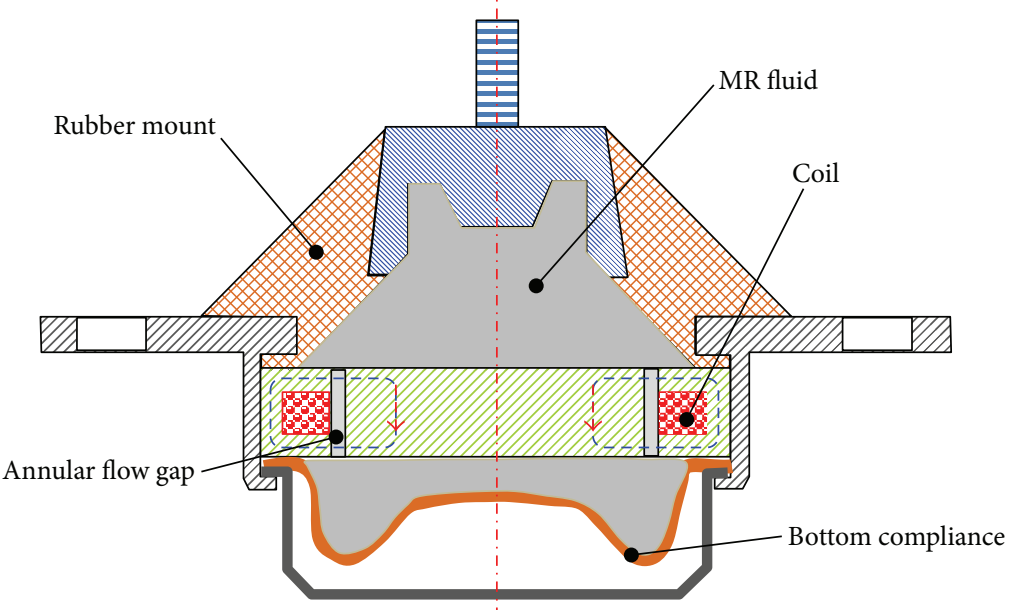

FIGURE 14: Cross section of MR mount based on hydraulic mount.

mount include operation mode of MR fluid, gap size of flow path, block-up phenomenon, movable parts during operation, and exciting magnitude and frequency. Besides, other factors such as appearance of coil, number of coil, and dimensions of coil should be also significantly considered for mount design. However, these factors closely relate to the magnitude of magnetic field and hence change the value of damping force. The arrangement of coil will directly impact to formulate the operating modes in the mount design procedures, and hence the designer should carefully consider the operating modes to achieve desired control performance before determining specific dimensions of MR mount.

\section{Analysis of High Loaded MR Mount}

In this section, the governing equations required to design of high loaded MR mount are reviewed and discussed.
Firstly, equations for calculating the inside pressure of MR valve with both annular and radial fluid flow path [9] are summarized. These equations are basic knowledge to obtain exactly damping force in design procedure. This structure is depicted in Figure 21. The pressure drop by the annular fluid flow gaps is determined as follows:

$$
\Delta P_{\mathrm{af}}=\Delta P_{\mathrm{a} \eta}+\Delta P_{\mathrm{a} \tau}=\frac{12 \eta Q_{\mathrm{af}} L_{\mathrm{af}}}{\pi d_{\mathrm{af}}^{3} R_{2}}+\frac{2 c_{\mathrm{af}} \tau_{\mathrm{af}} L_{\mathrm{af}}}{d_{\mathrm{af}}},
$$

where $\Delta P_{\mathrm{af}}$ is the pressure drop by the annular fluid flow gaps, $\Delta P_{\mathrm{a} \eta}$ is the viscous pressure of the annular fluid flow, $\Delta P_{\mathrm{a} \tau}$ is the field-dependent induced from the yield stress of the annular fluid flow, $d_{\mathrm{af}}$ is the damping gap of annular fluid flow, $Q_{\mathrm{af}}$ is the volumetric flow rate through annular section, $\eta$ is the MR fluid viscosity, $\tau_{\text {af }}$ is the dynamic yield stress of annular fluid flow, and $c_{\mathrm{af}}$ is the factor of the flow velocity 


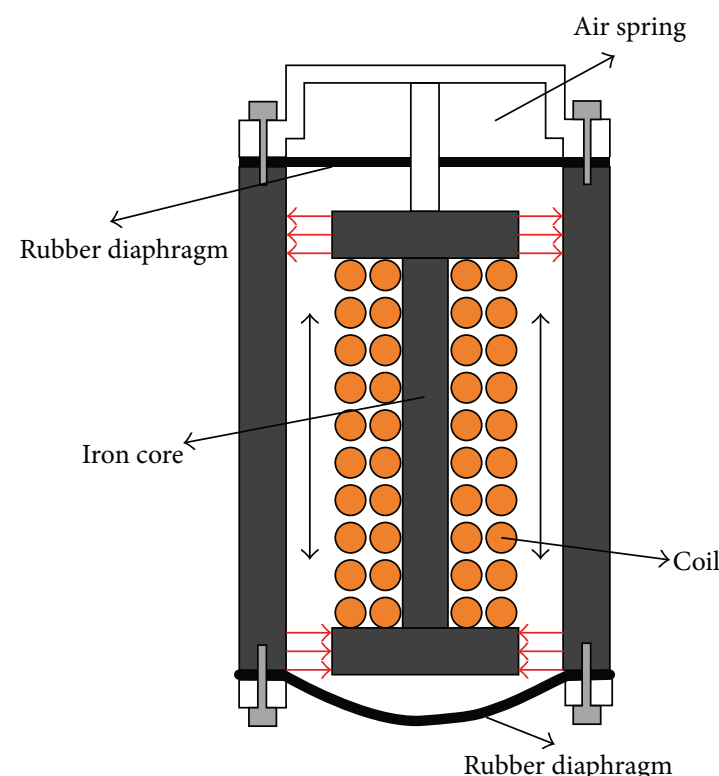

$\longleftrightarrow$ MR flow

$\longrightarrow$ Magnetic field

(a)
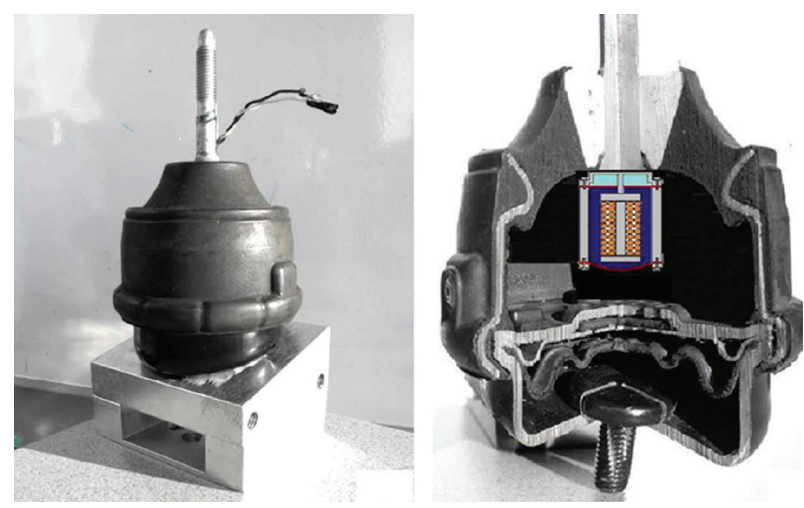

(b)

FIGURE 15: (a) Modified chamber and (b) MR mount with the modified chamber.

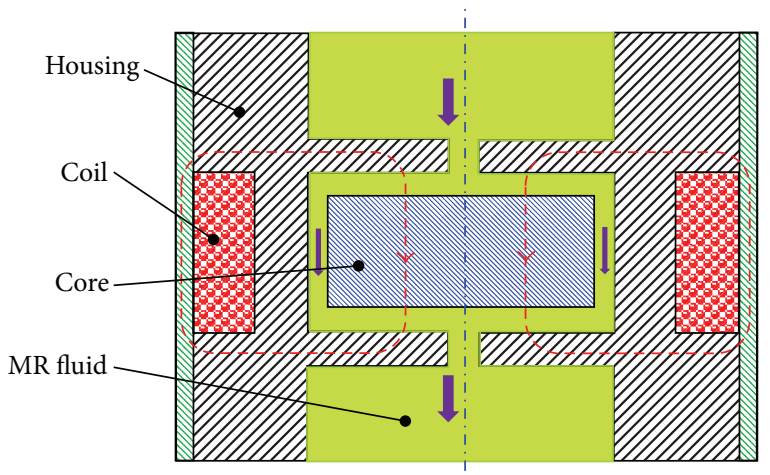

FIGURE 16: MR valve with external coil configuration.

profile. The pressure drop in the conflux flow which relates to the radial fluid flow is calculated as follows:

$$
\Delta P_{\eta \mathrm{rc}}=\int_{R_{1}}^{R_{0}} \frac{6 \eta Q_{\mathrm{rc}}}{\pi r d_{\mathrm{rf}}^{3}} d r=\frac{6 \eta Q_{\mathrm{rc}}}{\pi d_{\mathrm{rf}}^{3}} \ln \frac{R_{0}}{R_{1}}
$$

where $Q_{\mathrm{rc}}$ is the volumetric flow rate through radial section in conflux flow and $d_{\mathrm{rf}}$ is the damping gap of radial fluid flow. The pressure drop in the headstream flow which relates to the radial fluid flow is obtained as follows:

$$
\Delta P_{\eta \mathrm{rh}}=\int_{R_{0}}^{R_{1}} \frac{6 \eta Q_{\mathrm{rh}}}{\pi r d_{\mathrm{rf}}^{3}} d r=\frac{6 \eta Q_{\mathrm{rh}}}{\pi d_{\mathrm{rf}}^{3}} \ln \frac{R_{1}}{R_{0}}
$$

where $Q_{\mathrm{rh}}$ is the volumetric flow rate through radial section in headstream flow. The pressure drop related to the fielddependent component at radial fluid flow is derived by

$$
\Delta P_{\tau r}=\int_{R_{0}}^{R_{1}} \frac{c_{\mathrm{rf}} \tau_{\mathrm{rf}}}{d_{\mathrm{rf}}} d r=\frac{c_{\mathrm{rf}} \tau_{\mathrm{rf}}}{d_{\mathrm{rf}}}\left(R_{1}-R_{0}\right)
$$

where $\tau_{\mathrm{rf}}$ is the dynamic yield stress of radial fluid flow and $c_{\mathrm{rf}}$ is the factor of the flow velocity profile. Thus, the total pressure drop in the radial fluid flow gaps is expressed as

$$
\begin{aligned}
\Delta P_{\mathrm{rf}}= & \Delta P_{\eta \mathrm{rc}}+\Delta P_{\eta \mathrm{rh}}+2 \Delta P_{\tau r} \\
= & \frac{6 \eta Q_{\mathrm{rc}}}{\pi d_{\mathrm{rf}}^{3}} \ln \frac{R_{0}}{R_{1}}+\frac{6 \eta Q_{\mathrm{rh}}}{\pi d_{\mathrm{rf}}^{3}} \ln \frac{R_{1}}{R_{0}} \\
& +2 \frac{c_{\mathrm{rf}} \tau_{\mathrm{rf}}}{d_{\mathrm{rf}}}\left(R_{1}-R_{0}\right) .
\end{aligned}
$$

Now, the pressure drop in MR valve is summarized from (6) and (10) as follows:

$$
\Delta P=\Delta P_{\mathrm{af}}+\Delta P_{\mathrm{rf}} .
$$

Values of (11) are used for calculating damping force of MR valve. Based on this equation, damping forces for typical sections of high loaded mount are obtained. Consider one of sections for high loaded mount shown in Figure 22 in which the electric coil is designed as a trapezoid shape. This section can improve the magnetic line in the corner of upper/lower 


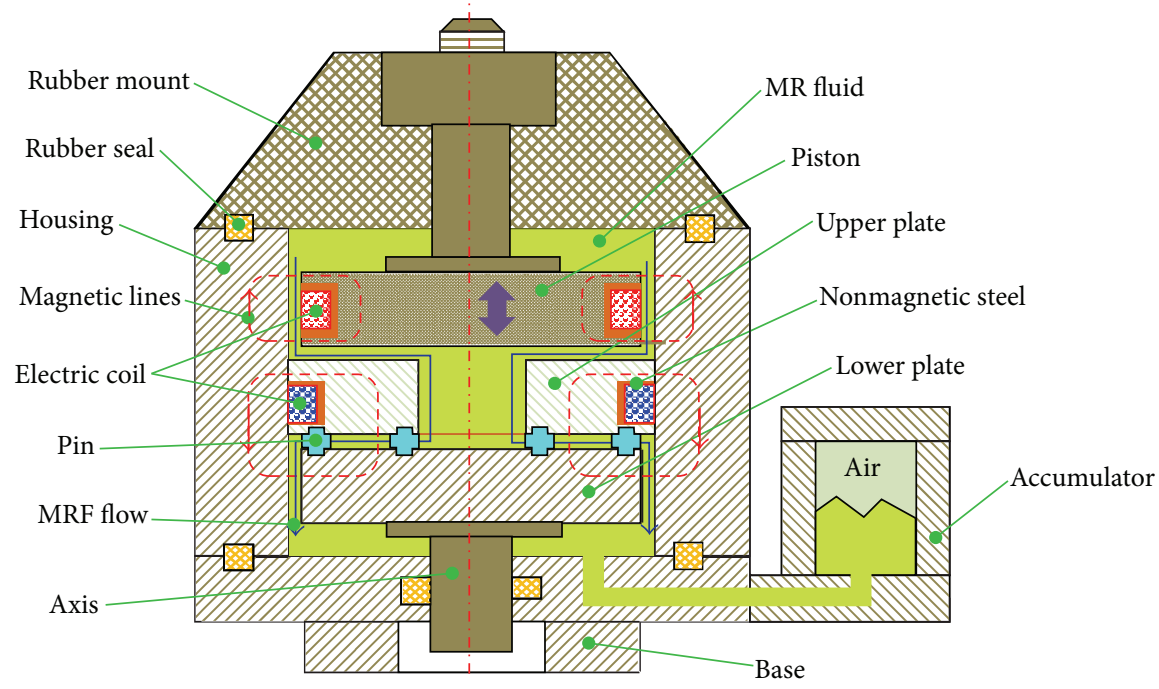

FIGURE 17: Configuration of high loaded MR damper-mount.

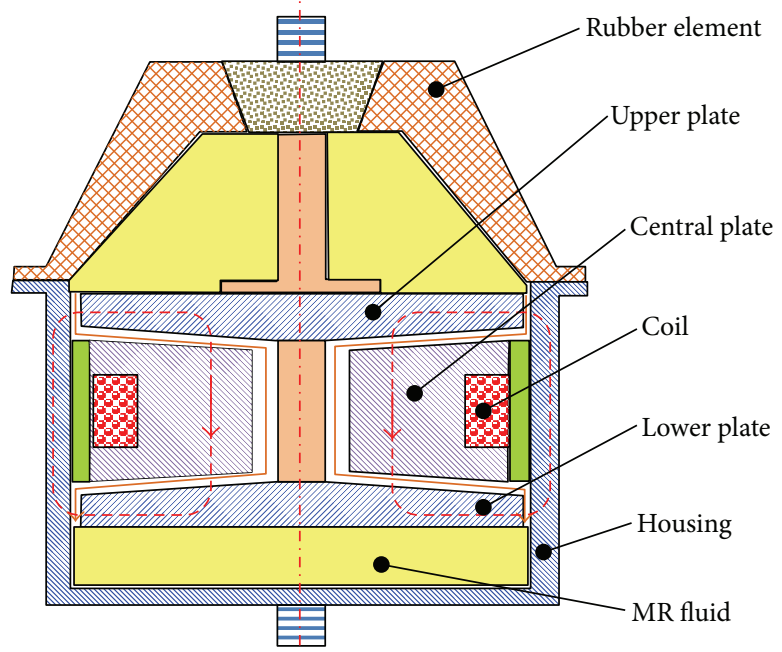

FIGURE 18: Configuration of MR mount with inclined gaps.

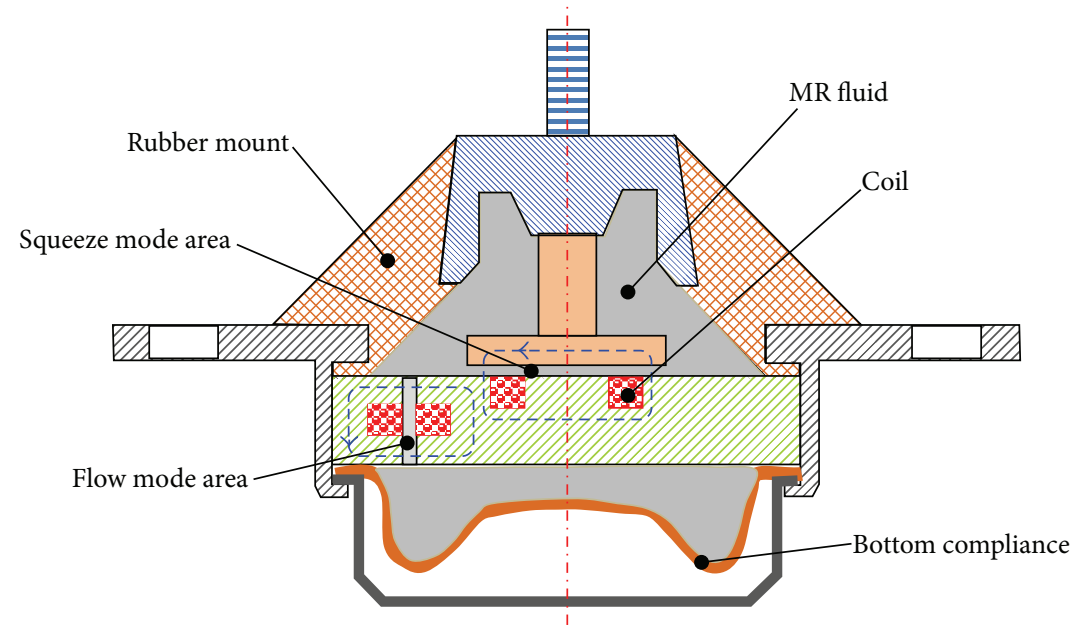

FIGURE 19: Configuration of the mixed mode MR mount. 


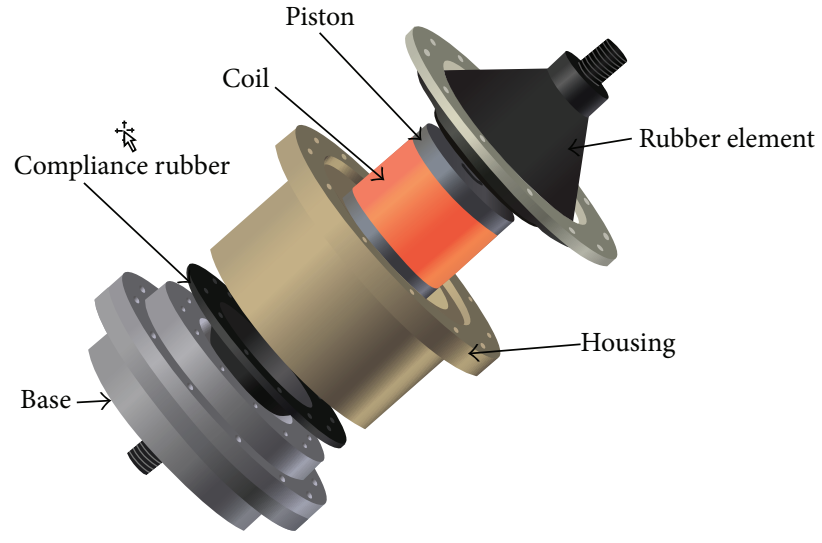

(a)

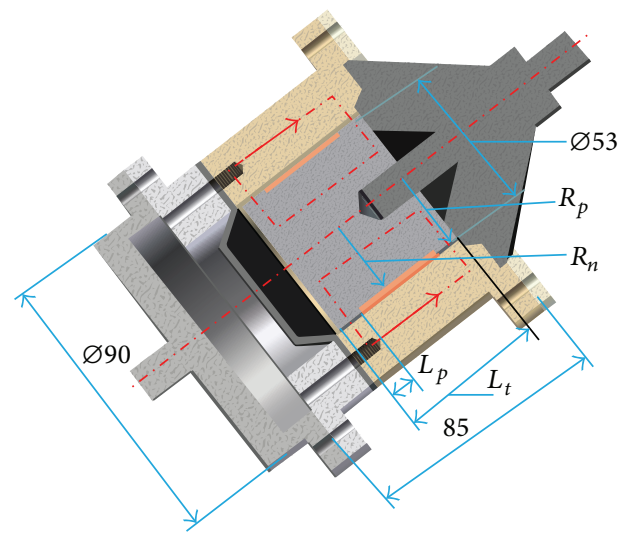

(b)

Figure 20: (a) Configuration of traditional MR mount and (b) cross section of traditional MR mount.
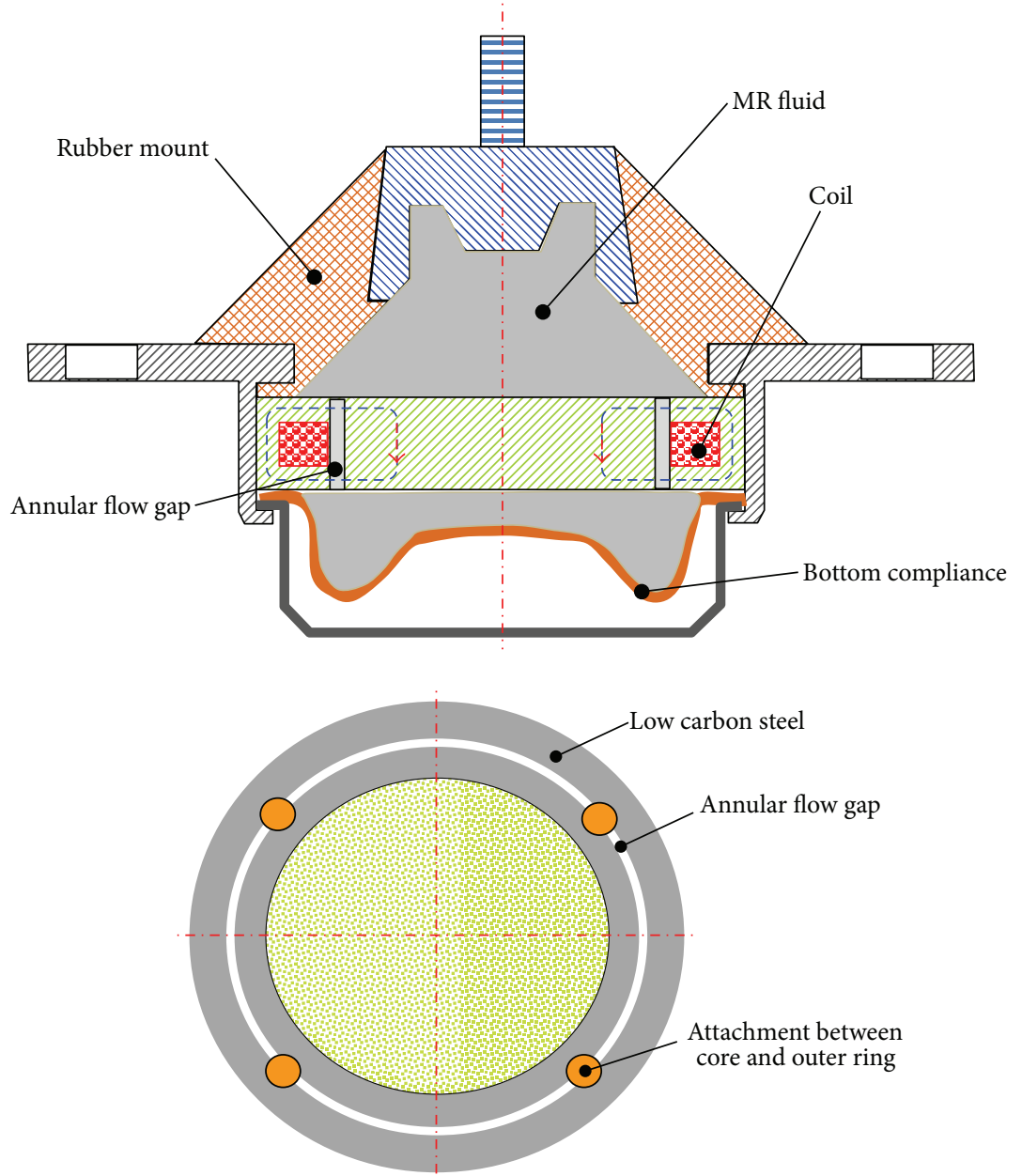

FIGURE 21: Cross section of MR mount based on hydraulic mount. 


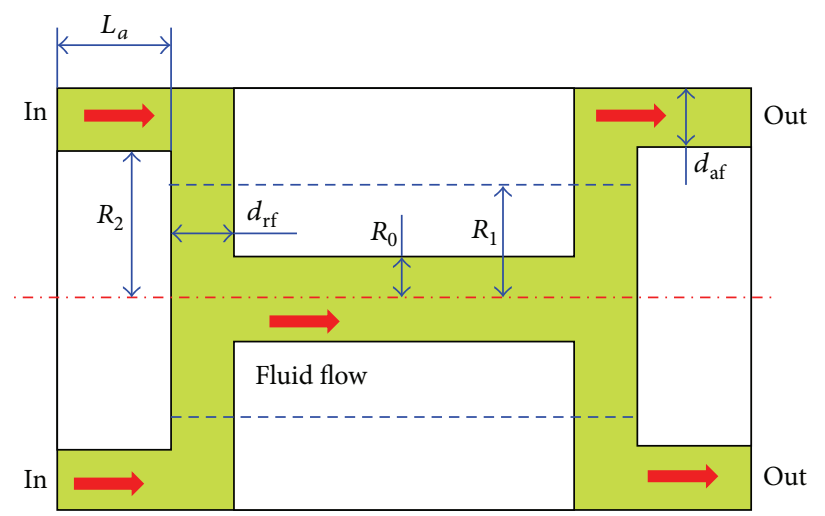

FIGURE 22: MR valve model with both annular and radial fluid flow paths.

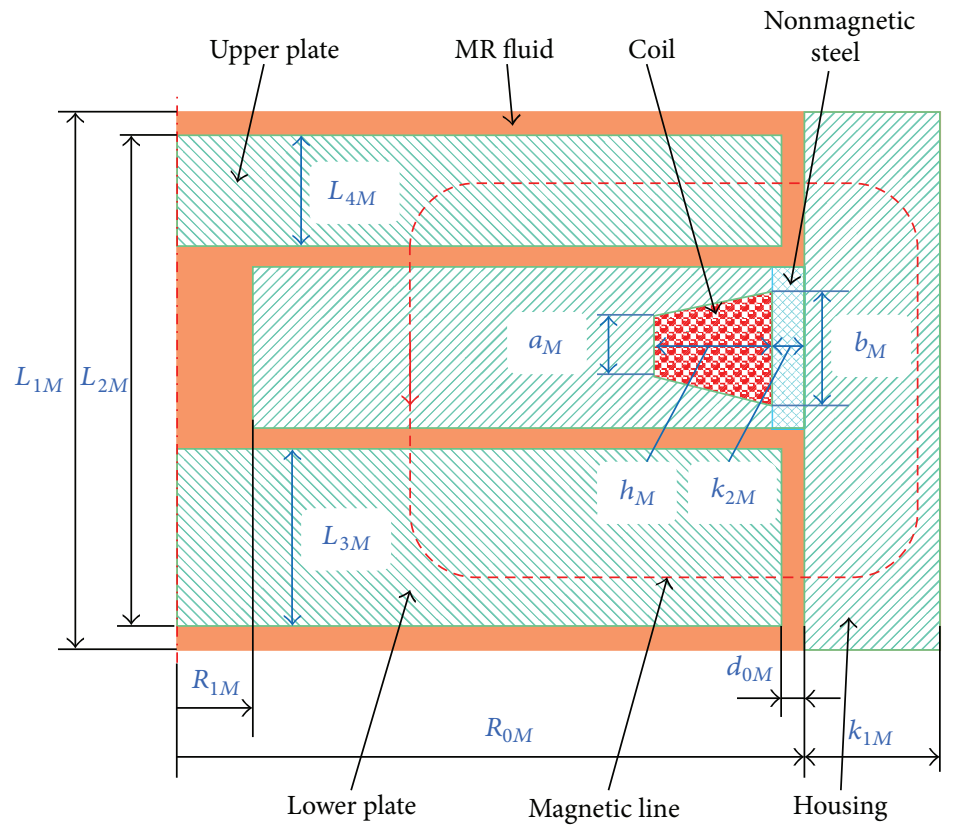

FIGURE 23: Section of MR valve for brake-mount structure.

plate and central plate. The damping force of MR mount for this section shown in Figure 23 is determined as follows:

$$
\begin{aligned}
F_{M} & =\left[\frac{6 \eta\left(L_{3 M}+L_{4 M}\right)}{\pi d_{0 M}^{3}\left(R_{0 M}-d_{0 M}\right)}+\frac{12 \eta}{\pi d_{0 M}^{3}} \ln \left(\frac{R_{0 M}-d_{0 M}}{R_{1 M}}\right)\right. \\
& \left.+\frac{16 \eta\left(L_{2 M}-L_{3 M}-L_{4 M}-2 d_{0 M}\right)}{\pi R_{1 M}^{4}}\right] A_{\mathrm{PISM}}^{2} v \\
& +\left[c_{a} \frac{\left(L_{3 M}+L_{4 M}\right)}{d_{0 M}} \tau_{y a}\right. \\
& \left.+2 c_{r} \frac{\left(R_{0 M}-R_{1 M}-d_{0 M}\right)}{d_{0 M}} \tau_{y r}\right] A_{\mathrm{PISM}} \operatorname{sgn}(v),
\end{aligned}
$$

where $F_{M}$ is the damping force $(\mathrm{N}), L_{3 M}$ is the height of lower plate $(\mathrm{m}), L_{4 M}$ is the height of upper plate $(\mathrm{m}), d_{0 M}$ is the damping gap (m), $\eta$ is the viscosity of MRF ( $\mathrm{Pa} \cdot \mathrm{s}), R_{0 M}$ is the efficient radius $(\mathrm{m}), R_{1 M}$ is the internal radius $(\mathrm{m}), L_{2 M}$ is the height of piston (m), $A_{\text {PISM }}$ is the area of piston related damping gap $d_{0 M}\left(\mathrm{~m}^{2}\right), c_{a}$ and $c_{r}$ are coefficients of flow, and $\operatorname{sgn}(v)$ is signum function of velocity $v$.

The section for the high loaded mount shown in Figure 24 is featured by changeable gaps of the mount. In this section structure, the gap position can be adjusted according to the difference pressure between upper chamber and lower chamber. Its damping force is calculated as follows [11]:

$$
\begin{aligned}
F_{M} & =\left[\frac{6 \mu\left(L_{1}+L_{2}\right)}{\pi d_{04}^{3}\left(R_{1}+R_{2}\right)}+\frac{12 \mu}{\pi d_{01}^{3}} \ln \left(\frac{R_{1}+R_{2}}{R_{1}}\right)\right. \\
& \left.+\frac{16 \mu\left(L-L_{1}-L_{2}-2 d_{04}\right)}{\pi R_{1}^{4}}+\frac{8 \mu L_{3}}{\pi F_{s}}\right] A_{\text {up }} v \\
+ & {\left[c_{1} \frac{\left(L_{1}+L_{2}\right)}{d_{04}} \tau_{1}+c_{2} \frac{R_{2}}{d_{01}} \tau_{2}+c_{3} \frac{\left(L_{31}+L_{32}\right)}{d_{05}} \tau_{3}\right] } \\
& \cdot A_{\text {up }} \operatorname{sgn}(v),
\end{aligned}
$$




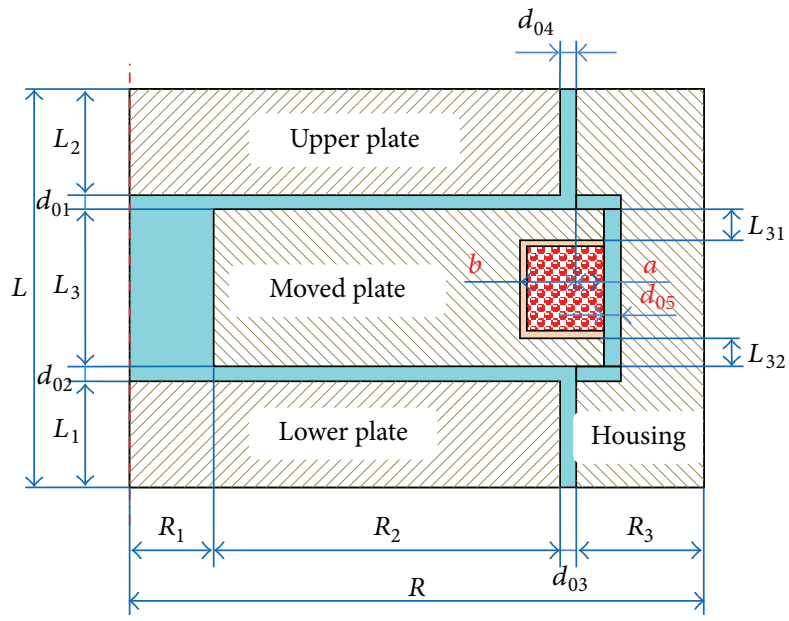

FIGURE 24: Section of MR valve with changeable damping gaps of mount.

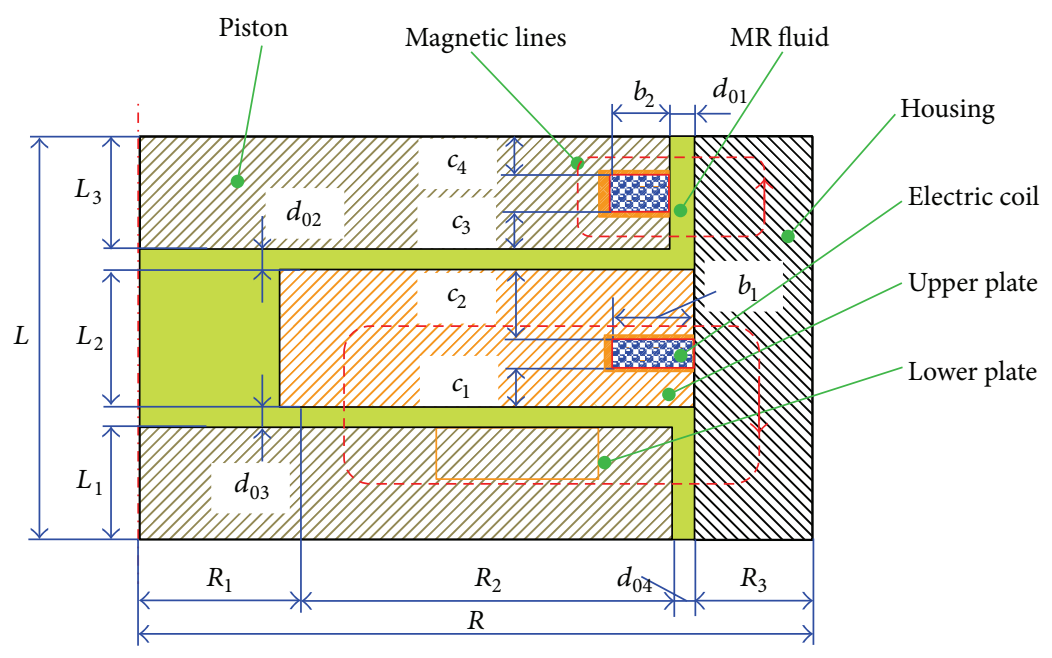

FIGURE 25: Section of MR valve for damper-mount structure.

where

$$
F_{s}=\frac{\left(R_{1}+R_{2}+d_{03}+a\right)^{4}-\left(R_{1}+R_{2}+d_{03}+a+d_{05}\right)^{4}+\left[\left(R_{1}+R_{2}+d_{03}+a+d_{05}\right)^{2}-\left(R_{1}+R_{2}+d_{03}+a\right)^{2}\right]^{2}}{\ln \left[\left(R_{1}+R_{2}+d_{03}+a+d_{05}\right) /\left(R_{1}+R_{2}+d_{03}+a\right)\right]},
$$

$A_{\text {up }}$ is the area of the upper plate, $v$ is the velocity of MR flow, $\mu$ is the base viscosity of MR fluid at off-state, $c_{1}, c_{2}$, and $c_{3}$ are chosen as constants whose values are from 2 to 3 , and $\tau_{1}$, $\tau_{2}$, and $\tau_{3}$ are the yield stresses of MR fluid at three different areas corresponding to three damping gaps $d_{04}, d_{01}$, and $d_{05}$.

The cross section used for high loaded damper-mount is depicted in Figure 25. Its damping force includes two main components: damper and mount. The damping force for damper part is calculated as follows [19]:

$$
F_{d 1}=P_{a} A_{s}+c_{v} v_{p}+f_{\mathrm{MR}} \operatorname{sgn}\left(v_{p}\right),
$$

where $P_{a}$ is the pressure in the gas chamber, $c_{v}$ is the viscous coefficient, $f_{\mathrm{MR}}$ is the yield stress force of the piston-type mount, and $v_{p}$ is the velocity of piston. These parameters are determined as follows:

$$
\begin{aligned}
P_{a} & =P_{0}\left(\frac{V_{0}}{V_{0}+A_{s} v_{p}}\right)^{\alpha}, \\
c_{v} & =\frac{12 \mu L_{3}}{\pi\left(R_{1}+R_{2}+d_{1} / 2\right) d_{1}^{3}}\left(A_{p}-A_{s}\right)^{2}, \\
f_{\mathrm{MR}} & =\left(A_{p}-A_{s}\right) \frac{c\left(c_{3}+c_{4}\right)}{d_{1}} \tau_{y} .
\end{aligned}
$$




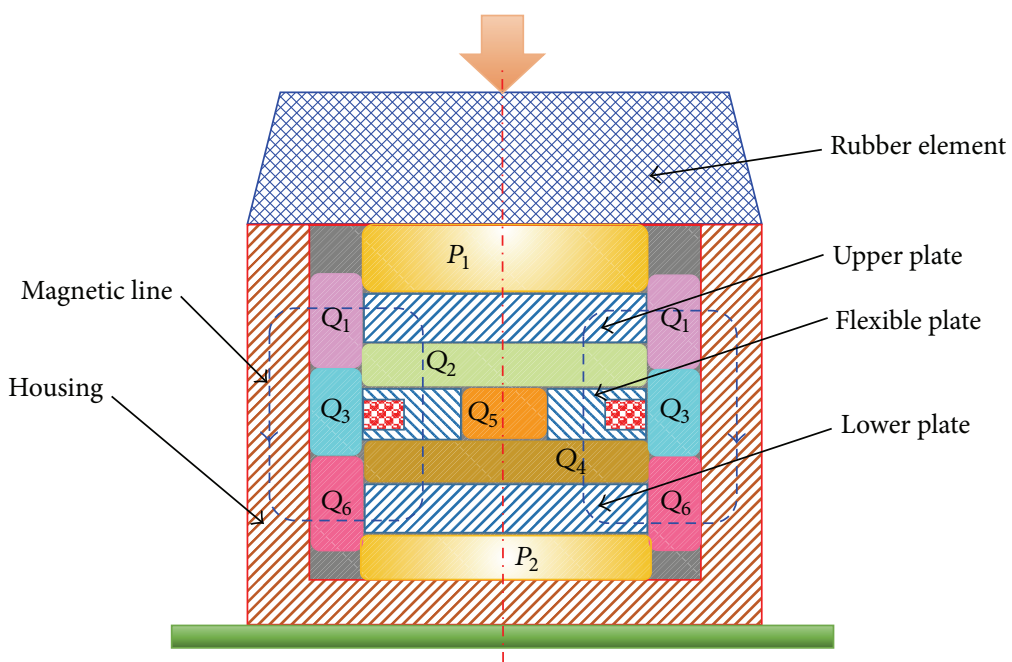

FIGURE 26: Distribution of inside pressures in mount.

The damping force for mount part is determined as follows:

$$
\begin{aligned}
F_{d 2} & =\left[\frac{6 \mu Q_{c}}{\pi d_{3}^{3}} \ln \left(\frac{R_{1}}{R_{1}+R_{2}+d_{4}}\right)\right. \\
& \left.+\frac{6 \mu Q_{h}}{\pi d_{3}^{3}} \ln \left(\frac{R_{1}+R_{2}+d_{4}}{R_{1}}\right)\right] A_{l}^{2} v_{p} \\
& +\left[\frac{c_{r} \tau_{y r}}{d_{4}}\left(R_{2}+d_{4}\right)+\frac{c_{r} \tau_{y r}}{d_{3}} R_{2}+\frac{c_{a} \tau_{y a}}{d_{4}} L_{1}\right] A_{l} \\
& \cdot \operatorname{sgn}\left(v_{p}\right),
\end{aligned}
$$

where $Q_{c}$ is the volumetric flow rate of central hole, $Q_{h}$ is the volumetric flow rate of horizontal damping gap between the piston and upper plate of the fixed valve, $A_{l}$ is the area of lower plate, and $c_{r}$ and $c_{a}$ are the coefficient pressure ratios.

\section{Analytical Tool for Mount Simulation}

There are two main approaches for simulating MR mount: CFD (Computation Fluid Dynamic) model in commercial software [27] and analytical model [28]. Besides, another analysis model as modified Bingham model [29] and modified Bouc-Wen model $[30,31]$ can be applied to derive the mount model. In this section, the analytical models which are frequently adopted for high loaded mount design are reviewed and discussed. It is noted here that the analytical tool used in [28] is possible to be used for the design of conventional MR mount with small damping force. Considering the distribution of flow rates inside MR mount shown in Figure 26, a simple mechanical model of MR mount can be expressed as shown in Figure 27. From this model, the total flow rate $Q$ of $M R$ fluid inside mount is written by

$$
Q=Q_{1}+Q_{2}+Q_{3}+Q_{4}+Q_{5}+Q_{6}=\sum_{I=1}^{6} Q_{i}
$$

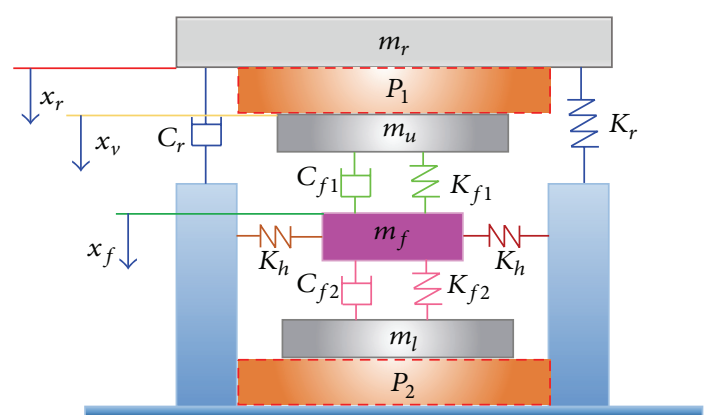

FIGURE 27: Mechanical model of MR mount.

where $Q_{1}$ is the flow rate of damping gap of upper plate $\left(\mathrm{m}^{3} / \mathrm{s}\right), Q_{2}$ is the flow rate of upper face of flexible plate $\left(\mathrm{m}^{3} / \mathrm{s}\right)$, $Q_{3}$ is the flow rate of outside flexible plate $\left(\mathrm{m}^{3} / \mathrm{s}\right), Q_{4}$ is the flow rate of lower face of flexible plate $\left(\mathrm{m}^{3} / \mathrm{s}\right), Q_{5}$ is the flow rate of central hole of flexible plate $\left(\mathrm{m}^{3} / \mathrm{s}\right)$, and $Q_{6}$ is the flow rate of damping gap of lower plate $\left(\mathrm{m}^{3} / \mathrm{s}\right)$. The displacements of the system include $x_{r}$ of rubber element, $x_{v}$ of valve block, and $x_{f}$ of flexible plate. The pressure of upper chamber is expressed by the following equation:

$$
\begin{gathered}
\frac{1}{\beta} \frac{\partial P_{1}}{\partial t}\left(V_{\text {up }}-A_{r} x_{r}+A_{f} x_{f}+A_{\text {up }} x_{v}\right)-\dot{x}_{r} A_{r} \\
+\dot{x}_{f} A_{f}+\dot{x}_{v} A_{\text {up }}+\sum_{i=1}^{6} Q_{i}=0
\end{gathered}
$$

where $\beta$ is the bulk modulus of $\mathrm{MR}$ fluid $\left(\mathrm{N} / \mathrm{m}^{2}\right), P_{1}$ is the upper chamber pressure $(\mathrm{Pa}), V_{\text {up }}$ is the upper chamber volume $\left(\mathrm{m}^{3}\right), A_{r}$ is the rubber element area which is contacted area with MR fluid $\left(\mathrm{m}^{2}\right), A_{f}$ is the flexible plate area $\left(\mathrm{m}^{2}\right)$, $A_{\text {up }}$ is the upper plate area $\left(\mathrm{m}^{2}\right), \dot{x}_{r}$ is the deformation velocity of rubber mount $(\mathrm{m} / \mathrm{s}), \dot{x}_{f}$ is the vibrated velocity of flexible 


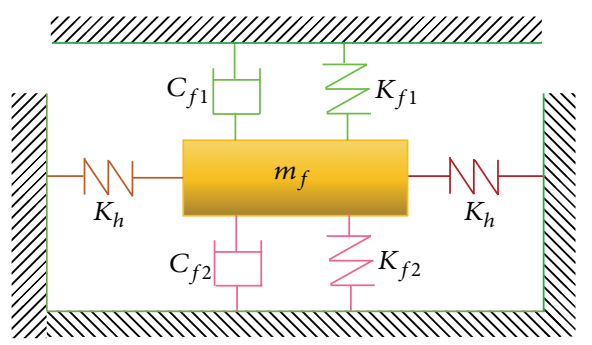

FIgURE 28: Flexible-valve model.

plate $(\mathrm{m} / \mathrm{s})$, and $\dot{x}_{v}$ is the velocity of valve block $(\mathrm{m} / \mathrm{s})$. The pressure of lower chamber is expressed as follows:

$$
\frac{1}{\beta} \frac{\partial P_{2}}{\partial t}\left(V_{\mathrm{lo}}-A_{f} x_{f}\right)-A_{f} \dot{x}_{f}-\sum_{i=1}^{6} Q_{i}=0
$$

where $P_{2}$ is the lower chamber pressure $(\mathrm{Pa})$ and $V_{\text {lo }}$ is the lower chamber volume $\left(\mathrm{m}^{3}\right)$. From Figure 28, the governing equation of flexible system is derived as follows:

$$
\begin{aligned}
& m_{f} \ddot{x}_{f}+\left(k_{f 1}+k_{f 2}\right) x_{f}+\left(c_{f 1}+c_{f 2}\right) \dot{x}_{f} \\
& \quad+2 k_{h}\left(1-\frac{l_{0}}{\sqrt{l^{2}+\left(x_{f}-x_{v}\right)^{2}}}\right)=P_{1} A_{\text {up }},
\end{aligned}
$$

where $m_{f}$ is the mass of flexible plate $(\mathrm{kg}), k_{f 1}$ is the upper stiffness coefficient of MR fluid $(\mathrm{N} / \mathrm{m}), k_{f 2}$ is the lower stiffness coefficient of MR fluid $(\mathrm{N} / \mathrm{m}), c_{f 1}$ is the upper damping coefficient of MR fluid $(\mathrm{Ns} / \mathrm{m}), c_{f 2}$ is the lower damping coefficient of MR fluid (Ns/m), $k_{h}$ is the horizontal stiffness coefficient of MR fluid $(\mathrm{N} / \mathrm{m}), l_{0}$ is the initial horizontal damping gap $(\mathrm{m})$, and $l$ is horizontal damping gap in vibration (m) [32]. It is noted that (19)-(21), the movement of upper plate and lower plate, are similar. These plates are supposed to be designed to guarantee motions simultaneously. The stiffness coefficients of MR fluid are calculated as follows [31]:

$$
\begin{aligned}
& k_{f 1}=c_{1}\left(\frac{A_{f}^{2}}{V_{01}}+\frac{A_{\mathrm{up}}^{2}}{V_{\mathrm{up}}}\right), \\
& k_{f 2}=c_{2}\left(\frac{A_{f}^{2}}{V_{02}}+\frac{A_{\mathrm{lo}}^{2}}{V_{\mathrm{lo}}}\right),
\end{aligned}
$$

where $c_{1}(\mathrm{GPa})$ and $c_{2}(\mathrm{GPa})$ are the bulk modulus of the fluidair mixture [33] of the upper face and lower face of flexible plate, respectively, $A_{\text {up }}$ is the upper plate area $\left(\mathrm{m}^{2}\right), A_{\mathrm{lo}}$ is the lower plate area $\left(\mathrm{m}^{2}\right), V_{01}$ is the upper volume at upper face of flexible plate $\left(\mathrm{m}^{3}\right)$, and $V_{02}$ is the lower volume at lower face of flexible plate $\left(\mathrm{m}^{3}\right)$. Equation (23) is redefined following the justification of flexible plate of valve block as follows:

$$
\begin{aligned}
& k_{f 1}=c_{k f 1} \sqrt{I}\left(\frac{A_{f}^{2}}{A_{\mathrm{up}} d_{01}}+\frac{A_{\mathrm{up}}^{2}}{V_{\mathrm{up}}}\right), \\
& k_{f 2}=c_{k f 2} \sqrt{I}\left(\frac{A_{f}^{2}}{A_{\mathrm{lo}} d_{02}}+\frac{A_{\mathrm{lo}}^{2}}{V_{\mathrm{lo}}}\right),
\end{aligned}
$$

where $c_{k f 1}\left(\mathrm{~N} / \mathrm{m}^{2} \cdot \mathrm{A}^{-1 / 2}\right)$ and $c_{k f 2}\left(\mathrm{~N} / \mathrm{m}^{2} \cdot \mathrm{A}^{-1 / 2}\right)$ are constants including the effect of bulk modulus. $I$ is applied current to the coil (A). When there are three parameters of the current $I$, the damping gaps $d_{01}, d_{02}$ are changed according to the vibration magnitude, and the stiffness $k_{f 1}$ and stiffness $k_{f 2}$ are also changed. This variation guarantees the stability of the system. The damping coefficients of MR fluid are calculated as follows [31]:

$$
\begin{aligned}
& c_{f 1}=\frac{\mu A_{f}}{d_{01}}\left(1+\frac{\tau_{y} d_{01}}{\eta v_{0}}\right), \\
& c_{f 2}=\frac{\mu A_{f}}{d_{02}}\left(1+\frac{\tau_{y} d_{02}}{\eta v_{0}}\right),
\end{aligned}
$$

where $d_{01}$ is the damping gap between the upper plate and upper face of flexible plate $(\mathrm{m}), d_{02}$ is the damping gap between the lower plate and lower face of flexible plate $(\mathrm{m}), \tau_{y}$ is the yield stress of MR fluid (Pa), and $v_{0}$ is the flow velocity of $\mathrm{MR}$ fluid $(\mathrm{m} / \mathrm{s})$. It is remarked that the variation of the applied current $I$ will influence the change of $\tau_{y}$, and then the values of $c_{f 1}$ and $c_{f 2}$ are also changed. From Figure 29, the governing magnetic circuit equation of MR mount is calculated as follows [28]:

$$
\dot{\phi}=\frac{e_{\mathrm{in}}}{N}-\left(\frac{R_{c}}{N}\right)\left(\frac{R_{\mathrm{to}}}{N}\right) \phi
$$

where $e_{\text {in }}$ is the supplied voltage $(\mathrm{V}), N$ is the number of turns in the electric coil (turns), $R_{c}$ is the resistance of the coil $(\Omega)$, and $\phi$ is the magnetic flux. $R_{\text {to }}$ is the total reluctance of the magnetic circuit in MR mount and calculated as follows:

$$
\begin{aligned}
R_{\mathrm{to}}= & \frac{1}{(2 \pi R) \mu_{\text {hous }}}+\frac{d_{04}}{\left(\pi R H_{1}\right) \mu_{d 1}}+\frac{d_{01}}{\left(2 \pi R_{f}\right) \mu_{d 2}} \\
& +\frac{d_{02}}{\left(2 \pi R_{f}\right) \mu_{d 3}}+\frac{1}{\left(2 \pi R_{f}\right) \mu_{f}}+\frac{d_{03}}{\left(\pi R H_{2}\right) \mu_{d 4}},
\end{aligned}
$$

where $\mu_{\text {hous }}, \mu_{d 1}, \mu_{d 2}, \mu_{d 3}$, and $\mu_{d 4}$ are permeability of the housing, damping gap $d_{04}$, damping gap $d_{01}$, damping gap $d_{02}$, and damping gap $d_{03}$, respectively. The damping force of MR mount is expressed as follows:

$$
\begin{aligned}
F_{\text {MRgen }}= & c_{\mathrm{mr}}\left(I, P_{1}\right) \dot{x}_{v}+k_{\mathrm{mr}}\left(I, P_{1}\right) x_{v} \\
& +\rho_{\mathrm{mr}}\left(I, P_{1}, \dot{x}_{v}\right) z\left(\dot{x}_{v}\right)
\end{aligned}
$$

where $c_{\mathrm{mr}}\left(I, P_{1}\right)[\mathrm{N} \cdot \mathrm{s} / \mathrm{m}]$ is the damping coefficient following the variations of the applied current $I$ and pressure $P_{1}$, 


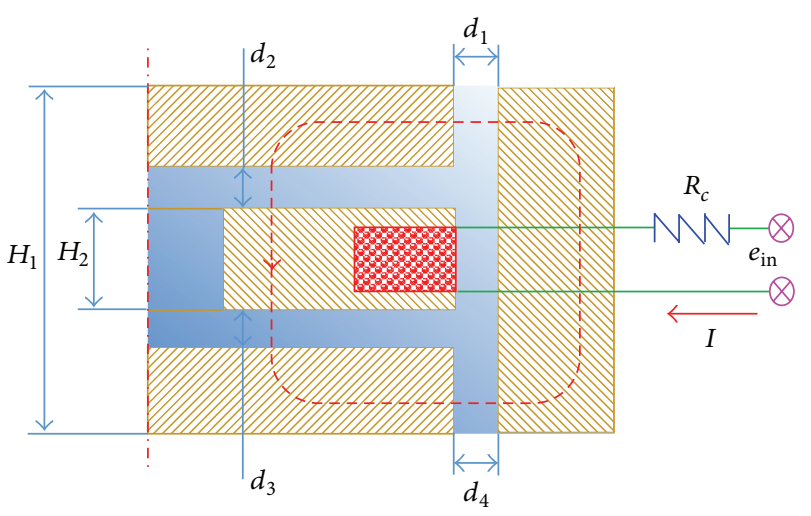

FIGURE 29: Magnetic circuit of the flexible-valve model.

$k_{\mathrm{mr}}\left(I, P_{1}\right)[\mathrm{N} / \mathrm{m}]$ is the stiffness coefficient, $\rho_{\mathrm{mr}}\left(I, P_{1}, \dot{x}_{v}\right)[\mathrm{N}]$ is the evolutionary coefficient, and $z\left(\dot{x}_{v}\right)$ is the evolutionary variable [31]. The components of (27) are determined as follows:

$$
\begin{aligned}
c_{\mathrm{mr}}\left(I, P_{1}\right) & =c_{m 1}+c_{m 2} \sqrt{I}+c_{m 3} \sqrt{\left|P_{1}\right|}, \\
k_{\mathrm{mr}}\left(I, P_{1}\right) & =k_{m 1}+k_{m 2} \sqrt{I}+k_{m 3} \sqrt{\left|P_{1}\right|} \\
\rho_{\mathrm{mr}}\left(I, P_{1}, \dot{x}_{v}\right) & =\rho_{m 1}+\rho_{m 2} \sqrt{I}+\rho_{m 3} \sqrt{|\dot{x}|}+\rho_{m 4} \sqrt{\left|P_{1}\right|} \\
\dot{z}(\dot{x}) & =-\gamma_{m}|\dot{x}||z| z+\gamma_{m} \dot{x},
\end{aligned}
$$

where $c_{m 1}, c_{m 2}, c_{m 3}, k_{m 1}, k_{m 2}, k_{m 3}, \rho_{m 1}, \rho_{m 2}, \rho_{m 3}, \rho_{m 4}$, and $\gamma_{m}$ are constants of damping coefficient, stiffness coefficient, evolutionary coefficient, and evolutionary variable, respectively. These values are determined based on results of optimization process. It is noted that these values will be different from experiment data where the group of $P_{1}$ seems to be a constant as reported in [31]. The total force of the mount $F_{m}$ system is determined as follows:

$$
F_{m}=F_{\text {MRgen }}-k_{r} x_{r}-c_{r} \dot{x}_{r},
$$

where $k_{r}$ is the stiffness of rubber element $(\mathrm{N} / \mathrm{m})$ and $c_{r}$ is the damping coefficient of rubber element $(\mathrm{N} \cdot \mathrm{s} / \mathrm{m})$. From (19), (20), (25), (27), and (29), the variables of the MR mount system are $u$ vector defined by

$$
\begin{aligned}
u= & \left\{u_{1}=P_{1}, u_{2}=P_{2}, u_{3}=x_{f}, u_{4}=\dot{x}_{f}, u_{5}\right. \\
& =Q_{1}, u_{6}=Q_{2}, u_{7}=Q_{3}, u_{8}=Q_{4}, u_{9}=Q_{5}, u_{10} \\
& \left.=Q_{6}, u_{11}=\phi\right\} .
\end{aligned}
$$

To evaluate the "block-up" phenomenon, the difference pressure between upper chamber and lower chamber is determined from the solving equations (18) and (19) and compared this result with the limited pressure which comes from the yield stress of MR fluid in magnetic field of upper chamber. The limited pressure is calculated as follows:

$$
\Delta P_{\mathrm{li}}=\frac{c \tau_{y} L_{2}}{d_{04}} .
$$

If the value of the difference is higher than the value of $\Delta P_{\mathrm{li}}$, the "block-up" phenomenon in the mount is prevented inversely.

\section{Conclusion}

In this paper, design configurations of high loaded MR mounts were reviewed and discussed by investigating advantages and disadvantages. It has been summarized from the design review that, in the design process of high loaded mounts, many principal factors such as damping gaps, cross sections, and equations of damping forces should be considered. In addition, identification models have to be considered simultaneously for the achievement of superior vibration control performance. It has been discussed that in general the high loaded MR mount is designed based on two main modes of MR fluid: flow mode and shear mode. The distribution of parts inside the mount determines the establishing pressures, which are directly related to the damping force of the mount. It has been also identified from the review investigation that the high loaded MR mount based on the squeeze mode is still difficult in design configuration due to the low damping force and leakage of the fluid itself. Hence, a breakthrough design configuration using the squeeze mode with large deformation values needs to be created in the future. This review investigation provided a useful guideline for designing high load MR mount by adopting combination modes of flow and shear based operation. This combination modes type of high loaded mounts has several benefits such as no occurrence of the block-up phenomenon and higher control force compared with a single mode.

\section{Nomenclature}

$\Delta P_{\mathrm{af}}:$ The pressure drop by the annular fluid flow gaps $(\mathrm{Pa})$

$\Delta P_{\mathrm{a} \eta}$ : The viscous pressure of the annular fluid flow $(\mathrm{Pa})$

$\Delta P_{\mathrm{a} \tau}$ : The field-dependent induced yield stress of the annular fluid flow $(\mathrm{Pa})$

$d_{\mathrm{af}}$ : The damping gap of annular fluid flow (m)

$Q_{\mathrm{af}}$ : The volumetric flow rate through annular section

$\eta$ : $\quad$ The MR fluid viscosity $(\mathrm{Pa} \cdot \mathrm{s})$

$\tau_{\mathrm{af}}$ : The dynamic yield stress of annular fluid flow $(\mathrm{kPa})$

$c_{\text {af }}$ : Factor of the flow velocity profile

$\Delta P_{\eta \mathrm{rc}}$ : The pressure drop in the conflux flow $(\mathrm{Pa})$

$Q_{\mathrm{rc}}$ : The volumetric flow rate through radial section in conflux flow $\left(\mathrm{m}^{3} / \mathrm{s}\right)$

$d_{\mathrm{rf}}: \quad$ The damping gap of radial fluid flow $(\mathrm{m})$

$\Delta P_{\eta \mathrm{rh}}$ : The pressure drop in the headstream flow (Pa)

$Q_{\mathrm{rh}}$ : The volumetric flow rate through radial section in headstream flow $\left(\mathrm{m}^{3} / \mathrm{s}\right)$

$\Delta P_{\tau r}:$ The pressure drop related to the field-dependent component at a radial fluid flow $(\mathrm{Pa})$ 
$\tau_{\mathrm{rf}}: \quad$ The dynamic yield stress of radial fluid flow $(\mathrm{kPa})$

$c_{\mathrm{rf}}$ : $\quad$ Factor of the flow velocity profile

$\Delta P_{\mathrm{rf}}$ : Total pressure drop in the radial fluid flow gaps $(\mathrm{Pa})$

$\Delta P: \quad$ The pressure drop in $\mathrm{MR}$ valve $(\mathrm{Pa})$

$F_{M}$ : The damping force $(\mathrm{N})$

$L_{3 M}$ : The height of lower plate (m)

$L_{4 M}$ : The height of upper plate (m)

$d_{0 M}: \quad$ The damping gap (m)

$R_{0 M}$ : The efficient radius ( $\mathrm{m}$ )

$R_{1 M}$ : The internal radius (m)

$L_{2 M}$ : The height of piston (m)

$A_{\text {PISM }}$ : The area of piston related damping gap $d_{0 M}\left(\mathrm{~m}^{2}\right)$

$\operatorname{sgn}(v)$ : Signum function of velocity $v$

$P_{a}: \quad$ The pressure in the gas chamber $(\mathrm{Pa})$

$f_{\mathrm{MR}}$ : The yield stress force of the piston-type mount $(\mathrm{N})$

$v_{p}: \quad$ The velocity of piston $(\mathrm{m} / \mathrm{s})$

$Q_{c}$ : $\quad$ The volumetric flow rate of central hole $\left(\mathrm{m}^{3} / \mathrm{s}\right)$

$Q_{h}: \quad$ The volumetric flow rate of horizontal damping gap between the piston and upper plate of fixed valve $\left(\mathrm{m}^{3} / \mathrm{s}\right)$

$Q_{1}$ : $\quad$ Flow rate of damping gap of upper plate $\left(\mathrm{m}^{3} / \mathrm{s}\right)$

$\mathrm{Q}_{2}$ : $\quad$ Flow rate of upper face of flexible plate $\left(\mathrm{m}^{3} / \mathrm{s}\right)$

$Q_{3}$ : $\quad$ Flow rate of outside flexible plate $\left(\mathrm{m}^{3} / \mathrm{s}\right)$

$Q_{4}$ : $\quad$ Flow rate of lower face of flexible plate $\left(\mathrm{m}^{3} / \mathrm{s}\right)$

$Q_{5}$ : $\quad$ Flow rate of central hole of flexible plate $\left(\mathrm{m}^{3} / \mathrm{s}\right)$

$Q_{6}$ : $\quad$ Flow rate of damping gap of lower plate $\left(\mathrm{m}^{3} / \mathrm{s}\right)$

$\beta: \quad$ Bulk modulus of MR fluid $\left(\mathrm{N} / \mathrm{m}^{2}\right)$

$P_{1}$ : $\quad$ Upper chamber pressure $(\mathrm{Pa})$

$V_{\text {up }}: \quad$ Upper chamber volume $\left(\mathrm{m}^{3}\right)$

$A_{r}$ : Rubber element area which is contacted area with MR fluid $\left(\mathrm{m}^{2}\right)$

$A_{f}: \quad$ Flexible plate area $\left(\mathrm{m}^{2}\right)$

$A_{\text {up }}: \quad$ Upper plate area $\left(\mathrm{m}^{2}\right)$

$\dot{x}_{r}$ : $\quad$ Deformation velocity of rubber mount $(\mathrm{m} / \mathrm{s})$

$\dot{x}_{f}$ : Vibrated velocity of flexible plate $(\mathrm{m} / \mathrm{s})$

$\dot{x}_{v}: \quad$ Velocity of valve block $(\mathrm{m} / \mathrm{s})$

$P_{2}$ : $\quad$ Lower chamber pressure $(\mathrm{Pa})$

$V_{\mathrm{lo}}$ : Lower chamber volume $\left(\mathrm{m}^{3}\right)$

$m_{f}$ : Mass of flexible plate $(\mathrm{kg})$

$k_{f 1}$ : Upper stiffness coefficient of MR fluid $(\mathrm{N} / \mathrm{m})$

$k_{f 2}$ : Lower stiffness coefficient of MR fluid $(\mathrm{N} / \mathrm{m})$

$c_{f 1}$ : Upper damping coefficient of MR fluid (Ns/m) $c_{f 2}$ : $\quad$ Lower damping coefficient of MR fluid (Ns/m)

$c_{1}, c_{2}$ : The bulk modulus of a fluid-air mixture of upper face and lower face of flexible plate (GPa)

$A_{\text {up }}: \quad$ Upper plate area $\left(\mathrm{m}^{2}\right)$

$A_{\mathrm{lo}}$ : $\quad$ Lower plate area $\left(\mathrm{m}^{2}\right)$

$V_{01}$ : $\quad$ Upper volume at upper face of flexible plate $\left(\mathrm{m}^{3}\right)$

$V_{02}$ : Lower volume at lower face of flexible plate $\left(\mathrm{m}^{3}\right)$

$c_{k f 1}, c_{k f 2}$ : Constants including the affection of bulk modulus $\left(\mathrm{N} / \mathrm{m}^{2} \cdot \mathrm{A}^{-1 / 2}\right)$

I: $\quad$ Applied current to the coil (A)

$e_{\text {in }}: \quad$ Supplied voltage $(\mathrm{V})$

$N$ : $\quad$ The number of turns in the electric coil (turns)

$R_{c}: \quad$ The resistance of the coil $(\Omega)$

$\phi: \quad$ The magnetic flux (Tesla).

\section{Conflict of Interests}

The authors declare that there is no conflict of interests.

\section{References}

[1] A. Geisberger, A. Khajepour, and F. Golnaraghi, "Non-linear modelling of hydraulic mounts: theory and experiment," Journal of Sound and Vibration, vol. 249, no. 2, pp. 371-397, 2002.

[2] H. Marzbani, R. N. Jazar, and M. Fard, "Hydraulic engine mounts: a survey," Journal of Vibration and Control, vol. 20, no. 10, pp. 1439-1463, 2014.

[3] Y. Yu, S. M. Peelamedu, N. G. Naganathan, and R. V. Dukkipati, "Automotive vehicle engine mounting systems: a survey," Journal of Dynamic Systems, Measurement and Control, vol. 123, no. 2, pp. 186-194, 2001.

[4] M. F. Golnaraghi and G. N. Jazar, "Development and analysis of a simplified nonlinear model of a hydraulic engine mount," Journal of Vibration and Control, vol. 7, no. 4, pp. 495-526, 2001.

[5] S. He and R. Singh, "Estimation of amplitude and frequency dependent parameters of hydraulic engine mount given limited dynamic stiffness measurements," Noise Control Engineering Journal, vol. 53, no. 6, pp. 271-285, 2005.

[6] Q. Li, J.-C. Zhao, B. Zhao, and X.-S. Zhu, "Parameter optimization of a hydraulic engine mount based on a genetic neural network," Proceedings of the Institution of Mechanical Engineers, Part D: Journal of Automobile Engineering, vol. 223, no. 9, pp. 1109-1117, 2009.

[7] F. Hausberg, C. Scheiblegger, P. Pfeffer, M. Plöchl, S. Hecker, and M. Rupp, "Experimental and analytical study of secondary path variations in active engine mounts," Journal of Sound and Vibration, vol. 340, pp. 22-38, 2015.

[8] M. Elahinia, C. Ciocanel, T. M. Nguyen, and S. Wang, "MR- and ER-based semiactive engine mounts: a review," Smart Materials Research, vol. 2013, Article ID 831017, 21 pages, 2013.

[9] D. H. Wang, H. X. Ai, and W. H. Liao, "A magnetorheological valve with both annular and radial fluid flow resistance gaps," Smart Materials and Structures, vol. 18, no. 11, Article ID 115001, 2009. 
[10] Q. H. Nguyen, S. B. Choi, Y. S. Lee, and M. S. Han, "Optimal design of high damping force engine mount featuring $M R$ valve structure with both annular and radial flow paths," Smart Materials and Structures, vol. 22, no. 11, Article ID 115024, 2013.

[11] D. X. Phu, K. Shah, and S.-B. Choi, "A new magnetorheological mount featured by changeable damping gaps using a movedplate valve structure," Smart Materials and Structures, vol. 23, no. 12, Article ID 125022, 2014.

[12] M.-S. Seong, S.-B. Choi, and C.-H. Kim, "Design and performance evaluation of MR damper for integrated isolation mount," Journal of Intelligent Material Systems and Structures, vol. 22, no. 15, pp. 1729-1738, 2011.

[13] D. York, X. Wang, and F. Gordaninejad, "A new magnetorheological mount for vibration control," Journal of Vibration and Acoustics, vol. 133, no. 3, Article ID 031003, 2011.

[14] O. H. Kang, W. H. Kim, W. H. Joo, and J. H. Park, "Design of the magnetorheological mount with high damping force for medium speed diesel generators," in Active and Passive Smart Structures and Integrated Systems, vol. 8688 of Proceedings of SPIE, San Diego, Calif, USA, March 2013.

[15] N. Q. Hung, P. D. Xuan, P. J. Hee, C. Seung-Bok, and K. O. Hyun, "Development of high damping magneto-rheological mount for ship engines," Applied Mechanics and Materials, vol. 336-338, pp. 953-959, 2013.

[16] Y. Rasekhipour and A. Ohadi, "Evaluating vibration performance of a semi-active MR engine mount," in Proceedings of the 2nd International Conference on Control, Instrumentation and Automation (ICCIA '11), pp. 90-95, IEEE, Shiraz, Iran, December 2011.

[17] H. Mansour, S. Arzanpour, M. F. Golnaraghi, and A. M. Parameswaran, "Semi-active engine mount design using auxiliary magneto-rheological fluid compliance chamber," Vehicle System Dynamics, vol. 49, no. 3, pp. 449-462, 2011.

[18] A. Y. Abd Fatah, S. A. Mazlan, T. Koga, H. Zamzuri, M. Zeinali, and F. Imaduddin, "A review of design and modeling of magnetorheological valve," International Journal of Modern Physics B, vol. 29, no. 4, Article ID 1530004, 2015.

[19] X. P. Do, J. U. Chung, and S. B. Choi, "Design and analysis of an innovative combined magneto-rheological damper-mount," in Active and Passive Smart Structures and Integrated Systems, vol. 9431 of Proceedings of SPIE, April 2015.

[20] J. U. Chung, X. P. Do, and S.-B. Choi, "Optimization of new magnetorheological fluid mount for vibration control of start/stop engine mode," in Active and Passive Smart Structures and Integrated Systems, vol. 9431 of Proceedings of SPIE, April 2015.

[21] D. X. Phu, N. V. Quoc, J.-H. Park, and S.-B. Choi, "Design of a novel adaptive fuzzy sliding mode controller and application for vibration control of magnetorheological mount," Proceedings of the Institution of Mechanical Engineers Part C: Journal of Mechanical Engineering Science, vol. 228, no. 13, pp. 2285-2302, 2014.

[22] S.-R. Hong and S.-B. Choi, "Vibration control of a structural system using magneto-rheological fluid mount," Journal of Intelligent Material Systems and Structures, vol. 16, no. 11-12, pp. 931-936, 2005.

[23] S.-R. Hong, S.-B. Choi, and M.-S. Han, "Vibration control of a frame structure using electro-rheological fluid mounts," International Journal of Mechanical Sciences, vol. 44, no. 10, pp. 2027-2045, 2002.
[24] S.-B. Choi, S.-R. Hong, K.-G. Sung, and J.-W. Sohn, "Optimal control of structural vibrations using a mixed-mode magnetorheological fluid mount," International Journal of Mechanical Sciences, vol. 50, no. 3, pp. 559-568, 2008.

[25] D. E. Barber and J. D. Carlson, "Performance characteristics of prototype MR engine mounts containing glycol MR fluids," Journal of Intelligent Material Systems and Structures, vol. 21, no. 15, pp. 1509-1516, 2010.

[26] Y.-T. Choi, N. M. Wereley, and Y.-S. Jeon, "Semi-active vibration isolation using magnetorheological isolators," Journal of Aircraft, vol. 42, no. 5, pp. 1244-1251, 2005.

[27] B. Tang and M. J. Brennan, "On the shock performance of a nonlinear vibration isolator with high-static-low-dynamicstiffness," International Journal of Mechanical Sciences, vol. 81, pp. 207-214, 2014.

[28] A. Farjoud, R. Taylor, E. Schumann, and T. Schlangen, "Advanced semi-active engine and transmission mounts: tools for modelling, analysis, design, and tuning," Vehicle System Dynamics, vol. 52, no. 2, pp. 218-243, 2014.

[29] A. Dominguez, R. Sedaghati, and I. Stiharu, "Modeling and application of MR dampers in semi-adaptive structures," Computers and Structures, vol. 86, no. 3-5, pp. 407-415, 2008.

[30] A. Domínguez-González, I. Stiharu, and R. Sedaghati, "Practical hysteresis model for magnetorheological dampers," Journal of Intelligent Material Systems and Structures, vol. 25, no. 8, pp. 967-979, 2014.

[31] P. Guo, X. Guan, and J. Ou, "Physical modeling and design method of the hysteretic behavior of magnetorheological dampers," Journal of Intelligent Material Systems and Structures, vol. 25, no. 6, pp. 680-696, 2014.

[32] S. B. Choi and Y. M. Han, Magnetorheological Fluid Technology: Applications in Vehicle Systems, CRC Press, Taylor \& Francis, Boca Raton, Fla, USA, 2013.

[33] S. R. Hong, N. M. Wereley, Y. T. Choi, and S. B. Choi, "Analytical and experimental validation of a nondimensional Bingham model for mixed-mode magnetorheological dampers," Journal of Sound and Vibration, vol. 312, no. 3, pp. 399-417, 2008. 

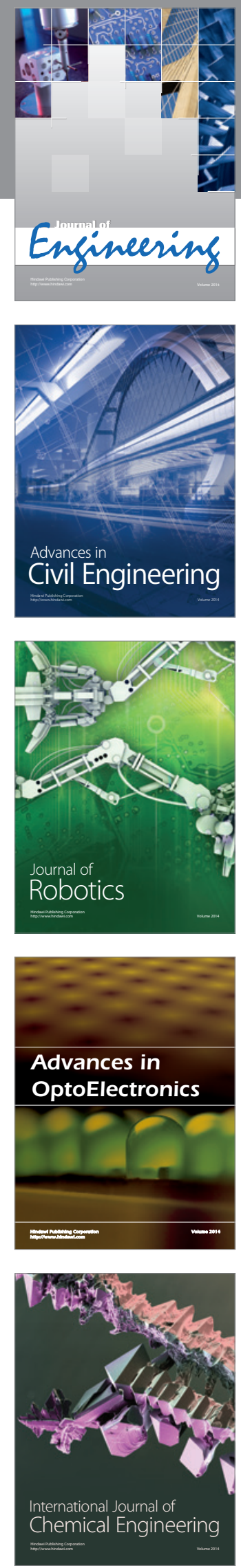

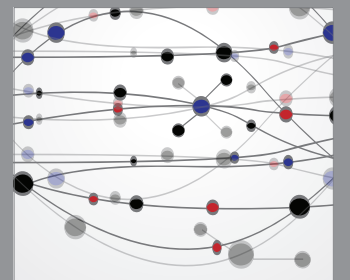

The Scientific World Journal
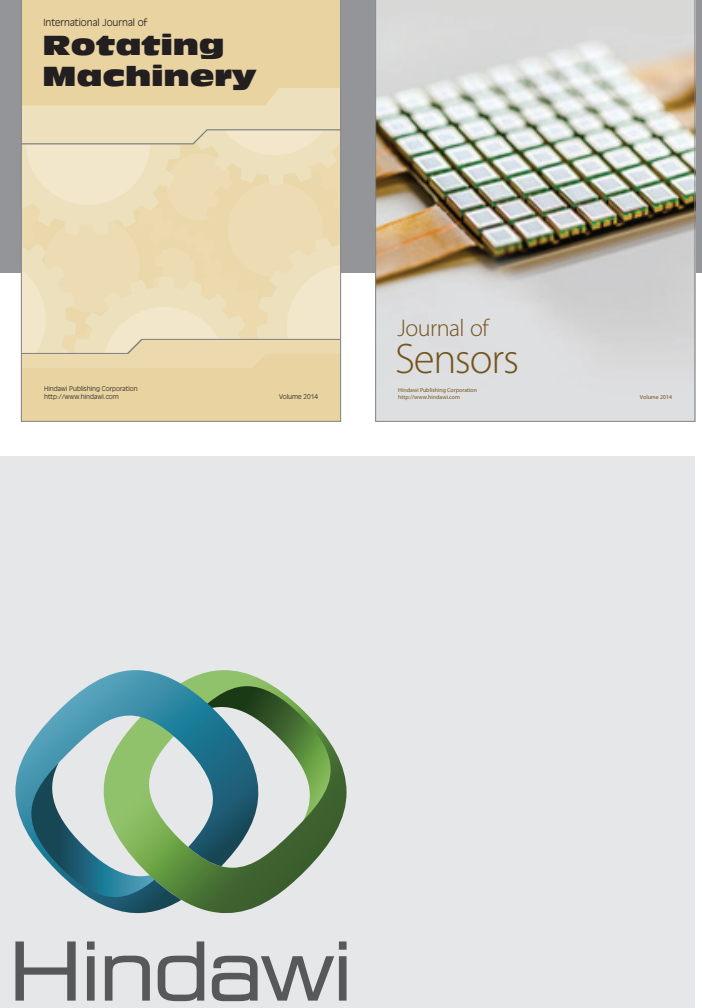

Submit your manuscripts at http://www.hindawi.com
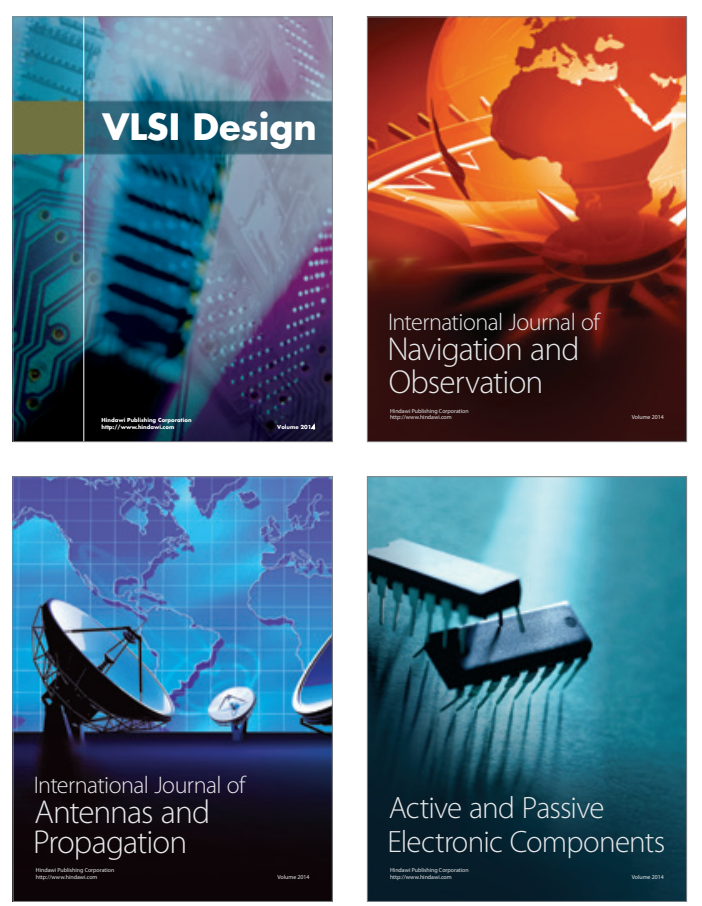
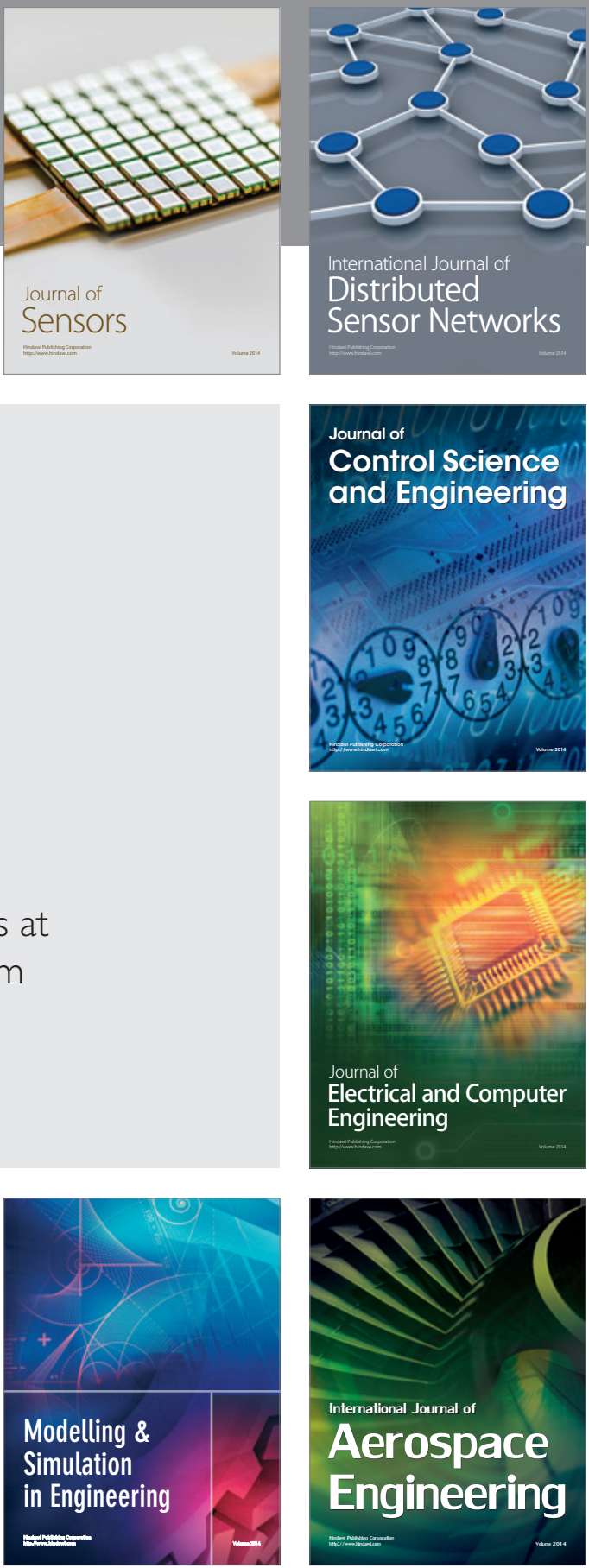

Journal of

Control Science

and Engineering
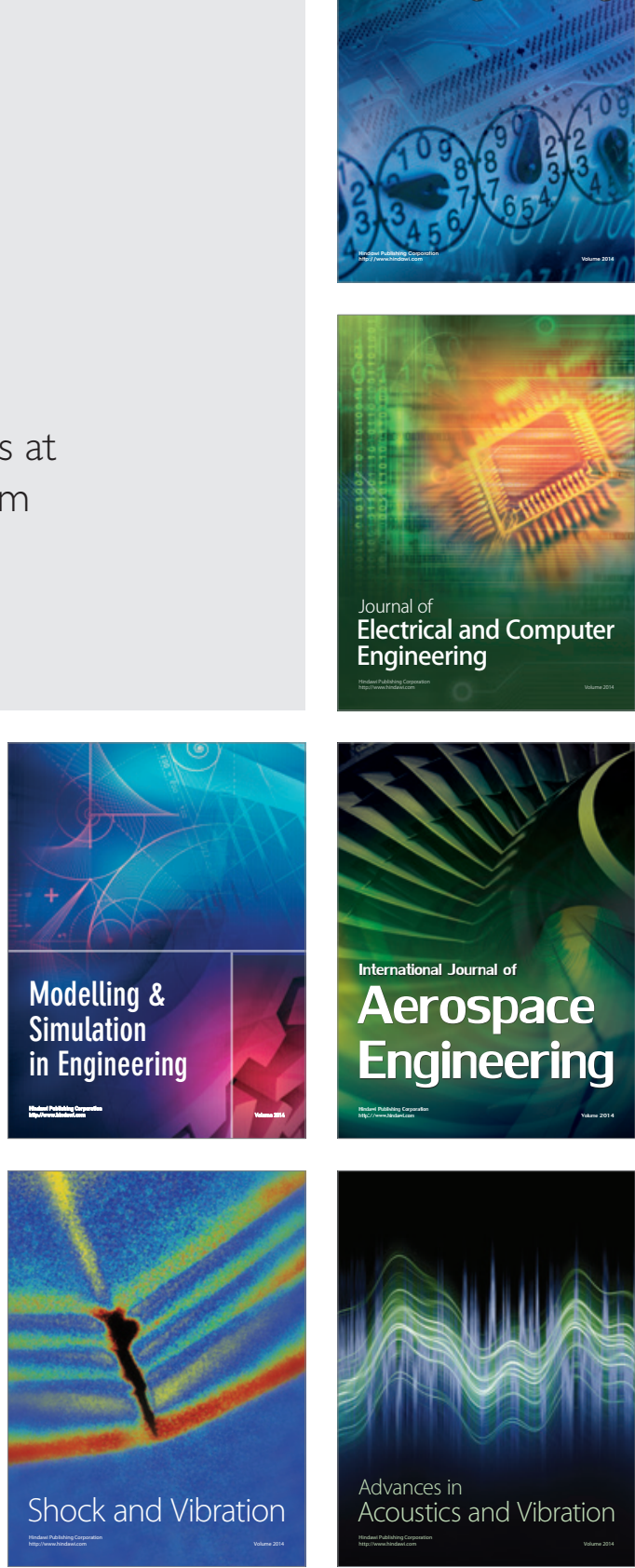